\title{
Spousal Labor Supply and Unemployment: Estimates from a Household Search Model
}

\author{
Jonathan Eggleston \\ Crozet, VA \\ M.A., University of Virginia, 2010 \\ B.A., College of William and Mary, 2009
}

A Dissertation Presented to the Graduate Faculty of the University of Virginia in Candidacy for the Degree of Doctor of Philosophy

Department of Economics

University of Virginia

May, 2014 


\begin{abstract}
The majority of job search models assume decision making takes place on the individual level, while in practice many people coordinate their labor market activity with a spouse. In this paper, I develop a job search model in which married couples jointly decide both how much to save and whether to accept or reject new job offers based on their current assets, wages, and unemployment insurance (UI) benefits. I am able to account for the endogeneity in these key variables through exclusion restrictions, variation in state UI laws and unemployment rates, theoretical restrictions on the hazards out of and into employment, and incorporation of various forms of unobserved heterogeneity in my model. I estimate my model with the 2004 and 2008 Panels of the Survey of Income and Program Participation using a modified version of a newly developed Bayesian Markov chain Monte Carlo algorithm, which I enhance to handle the sizable number of state variables in my model. My policy simulations show that both assets and spousal employment affect a household's responsiveness to changes in UI benefits, and that an estimated $75 \%-88 \%$ of the effect of UI on job search behavior is due to the liquidity-constraint effect, while only $12 \%-25 \%$ of the effect is due to the moral hazard effect.
\end{abstract}

JEL Classification: D10, H31, J22, J64, J65

Keywords: Job Search, Household Search, Liquidity Constraints, Unemployment Insurance, Added Worker Effect, Bayesian Markov chain Monte Carlo 


\section{Acknowledgments}

I would like to thank my advisors Steven Stern, Sarah Turner, and Leora Friedberg for their time and guidance and Shigehiro Oishi for serving as the outside reader for my dissertation committee. I have benefited from conversations with speakers for the Bankard Public Economics workshop and the Bankard Applied Microeconomics workshop, such as Matthew Notowidigdo, Andrew Ching, Chris Timmins, Allesandra Voena, and Jeremy Lise. I am grateful for the help of graduate students in the Economics Department, particularly Catherine Alford, Alicia Baik, Andriy Blokhin, Selcen Cakir, Nick Embrey, Amanda Kurzendoerfer, Mike LaForest, Ignacio Martinez, Charles Murry, Heidi Schramm, Huzeyfe Torun, and Zhou Zhang, who have helped me edit my writing and prepare for presentations. I would also like to thank the University of Virginia's Bankard Fund for financial support, my wife Casey Eggleston for her help editing my paper, and members of the Chi Alpha graduate Bible studies for their emotional and spiritual support. Any errors are my own. 


\section{Contents}

1 Introduction 1

2 Literature Review and Contribution $\quad 4$

2.1 Added Worker Effect . . . . . . . . . . . . . . . . . 4

2.2 Liquidity Constraints and UI Benefits . . . . . . . . . . . . . 6

2.3 Household Search Papers . . . . . . . . . . . . . . . . . . . . 7

$\begin{array}{llr}3 & \text { Model } & 8\end{array}$

3.1 Arrival of Job Offers . . . . . . . . . . . . . . . 9

3.2 Acceptance and Savings Choice . . . . . . . . . . . . . . . 10

3.2.1 Utility Flow . . . . . . . . . . . . . . . . . 10

3.2.2 Budget Constraint . . . . . . . . . . . . . . . 11

3.3 Birth, Job Loss, and UI Receipt . . . . . . . . . . . . . . . 12

3.4 Evolution of Unemployment Rates and UI Benefits . . . . . . . . . 13

3.5 Value Function . . . . . . . . . . . . . . . . . . . . 14

4 Identification $\quad 14$

4.1 Utility Function and Wage Distribution Parameters . . . . . . . . . . 15

4.2 Job Offer and Job Loss Probability Parameters . . . . . . . . . . . 16

4.3 Correcting for Endogeneity of Key Variables . . . . . . . . . . . . . . 18

5 Data $\quad 19$

5.1 Summary Statistics . . . . . . . . . . . . . . 20

5.2 Unemployment Insurance . . . . . . . . . . . . . . . . . . . . 23

5.3 Descriptive Probit Model . . . . . . . . . . . . . . . . . 26

6 Estimation and Computation $\quad 28$ 
6.1 Bayesian Statistics . . . . . . . . . . . . . . . . . . . . 29

6.2 Value Function Approximation . . . . . . . . . . . . . . . . 31

6.3 Modifications to IJC (2009) Algorithm . . . . . . . . . . . . 32

6.4 Likelihood Construction . . . . . . . . . . . . . . . . . 33

6.5 Functional Form Assumptions . . . . . . . . . . . . . . . . 34

6.6 Measurement Error . . . . . . . . . . . . . . . . . 35

$\begin{array}{lll}7 & \text { Results } & 37\end{array}$

7.1 Parameter Estimates . . . . . . . . . . . . . . . . 37

7.2 Goodness-of-Fit . . . . . . . . . . . . . . . . . . 41

7.3 Policy Simulations on UI Maximum Benefits . . . . . . . . . . . . 45

7.4 Moral Hazard vs. Liquidity Constraints in UI Benefits . . . . . . 50

7.5 Policy Experiments on the Maximum Duration of Benefits . . . . . 51

8 Conclusion $\quad 55$

$\begin{array}{ll}\text { A Appendix } & 61\end{array}$

A.1 Data Appendix . . . . . . . . . . . . . . . . 61

A.1.1 Sample Selection Criteria . . . . . . . . . . . . . . . 61

A.1.2 Variable Definitions . . . . . . . . . . . . . . . . 61

A.2 Estimation Appendix . . . . . . . . . . . . . . . 64

A.2.1 Value Function Approximation _. . . . . . . . . 64

A.2.2 Interpolation Function $\ldots \ldots \ldots \ldots 6$

A.2.3 Blocks . . . . . . . . . . . . . . . . . . 67

A.3 Likelihood Function . . . . . . . . . . . . . . 67

A.4 Supplemental Tables and Figures $\ldots \ldots \ldots \ldots \ldots$ 


\section{Introduction}

Understanding the effect of social insurance programs on the behavior of job seekers has important implications for how these programs should be designed. One such program that has undergone massive changes during the Great Recession is the unemployment insurance (UI) system in the United States. A type of econometric and theoretical model that provides valuable insights about unemployment duration and the effect of UI benefits on employment transitions is the job search model. However, while almost all job search models assume that decisions are made by individuals acting alone, in practice, many people coordinate their labor market activity with a spouse. For example, if a husband loses his job when his wife is not working, he may take the first available job in order to start replacing his lost income. Alternatively, he and his wife could decide that he should hold out for a better-paying job if his wife is able to find employment to support the family in the meantime, especially if he is receiving generous UI benefits. Ignoring spousal coordination may hamper our understanding of how married couples behave in the labor market and respond to UI benefits, particularly during periods of extensive unemployment resulting from recessions.

In this paper, I develop a job search model in which married heterosexual couples decide jointly whether to accept or reject new job offers based on their current assets, wages, UI benefits, and expectations about future job offers. My model allows me to study how married couples adjust their job search strategies when one spouse loses a job. To identify the parameters in my model, I make use of the following restrictions and features of my data: exclusion restrictions on the utility function and wage distributions; restrictions imposed by my search model on the observed hazards out of and into employment; the plausibly exogenous variation in UI laws across states; and the substantial variation in the unemployment rate across my 
sample. Employing these identification strategies and incorporating various forms of unobserved heterogeneity in my model allow me to account for the endogeneity in savings, spousal labor supply, wages, and UI benefits. Dealing with potential endogeneity problems in these key variables is one way in which I contribute to the literature on the added worker effect, UI and liquidity constraints, and household search models.

I estimate my model with the 2004 and 2008 Panels of the Survey of Income and Program Participation (SIPP) using a modified version of the Bayesian Markov chain Monte Carlo (MCMC) algorithm developed by Imai, Jain, and Ching (2009). The IJC (2009) algorithm reduces the computational burden of evaluating both the value function and the likelihood function, which, in this research, would be timeconsuming because I have an infinite-horizon model with a large number of unobserved variables. The enhancements I make to this algorithm allow me to handle the sizable number of state variables present in my model. I use the SIPP for my estimation because it contains a large number of married households, high-frequency employment data, and data on UI receipt. The time frame of my SIPP sample includes years immediately before and after the start of the Great Recession, which allows me to explore how substantial changes in the macroeconomic environment affect household search behavior.

After estimating the model, I conduct policy simulations to evaluate how both assets and spousal employment affect a household's responsiveness to changes in UI benefits. For example, I examine how changes in state UI maximum benefit amounts affect re-employment six months after a husband's job loss. The results show that households which had no assets and only the husband working prior to the husband's job loss are moderately responsive to UI variation, in terms of the likelihood of reemployment after six months. However, such households become $88 \%$ less responsive 
to changes in the UI maximum if, instead, they had assets at the time of the job loss. Incorporating this comparison of households with and without assets into my policy simulations allows me to connect my model to the discussion in economics started by Chetty (2008) on moral hazard versus liquidity constraints in UI benefits. This debate focuses on whether the effect of UI on unemployment durations is primarily due to a more negative channel of distorting the incentive to work, which Chetty (2008) refers to the "moral hazard" effect, or whether the effect of UI on unemployment durations is primarily due to a more positive channel of giving people without financial resources the ability to smooth consumption across an unemployment spell, which Chetty (2008) labels the "liquidity constraint" effect. The moral hazard and liquidity constraint effects can also be interpreted as substitution and income effects, receptively, since the former refers to how an increase in UI may decrease the relative benefit of receiving a labor income, while the latter refers to how UI may give a household more financial resources during an unemployment spell. By using my policy simulations and comparing the response of household with and without assets to changes in UI benefits, I find that $75 \%-88 \%$ of the effect of UI on job search behavior is due to the liquidity-constraint effect, while only $12 \%-25 \%$ of the effect is due to the moral hazard effect, depending on whether I focus on the employment probabilities of the husband or the wife. These results are somewhat similar to Chetty (2008) who finds that $60 \%$ of the effect of UI on unemployment durations for the general population is due to the liquidity-constraint effect, although my estimates of the proportion due to the liquidity-constraint effect are higher. Overall, my results provide evidence that UI mainly helps households smooth consumption rather than distorting the incentive to work.

The rest of this paper proceeds as follows: In Section 2, I discuss how my project relates to the literature on the added worker effect, liquidity constraints and UI ben- 
efits, and household search models. I then present my model in Section 3 and explain how the model is identified in Section 4. Section 5 describes my dataset, and Section 6 presents the Bayesian MCMC algorithm I use to estimate my model. In Section 7, I present estimates of my structural parameters as well as the results from my policy simulations. Finally, Section 8 concludes. In the appendix, I present a more detailed discussion of my data in A.1, a more detailed discussion of my estimation algorithm in A.2, my likelihood function in A.3, a table of the mathematical notation used in this paper in Table 16, and a flowchart describing my model in Figure 5.

\section{Literature Review and Contribution}

In this section, I discuss how my paper relates to three bodies of literature: the added worker effect, UI and liquidity constraints, and household search models. In general, my work contributes to these three branches of literature by allowing for spousal labor supply and assets to be endogenous. My paper is also the first to analyze liquidity constraints using a household search model, which I am able to do through the inclusion of assets and variation in UI maximum benefits and replacement rates in my model.

\subsection{Added Worker Effect}

The prior literature on the added worker effect examines whether wives increase their labor supply when their husbands become unemployed. Most papers in this literature study the added worker effect using reduced form methodology in which an indicator of the husband's unemployment is the key right-hand-side variable. ${ }^{1}$ Overall, the literature produces conflicting results on the prevalence of the added worker effect in the United States. Heckman and MaCurdy (1982), Lundberg (1985), Spletzer (1997), Tano (1993), and Stephens (2002) find a positive association between

\footnotetext{
${ }^{1}$ Some exceptions are Heckman and MaCurdy (1982), which derives a linear equation for the wife's labor supply from a structural model; Tano (1993), which studies the added worker effect with aggregate time-series data; and some of the household search papers discussed in section 2.3.
} 
a wife's labor supply and a husband's unemployment. However, Layard, Barton, and Zabalza (1980), Maloney (1987), and Maloney (1991) do not find a significant relationship, although Maloney (1987) does find a positive relationship for the wife's desired hours of work once the wife's unemployment or underemployment is accounted for. Because there are mixed results in this literature, other researchers have further explored the factors that could influence a wife's responsiveness to her husband's job loss. Cullen and Gruber (2000), for example, hypothesize that some studies might have failed to find a significant relationship due to the effects of the UI system. Cullen and Gruber (2000) use variation in state UI laws to find that wives are more likely to increase their labor supply if they live in a state with less generous UI benefits, but on average this increase in labor supply is not sufficient to replace the husband's income. Some additional studies suggest that the added worker effect may vary across the population and across time. Mattingly and Smith (2010), for example, found that wives of unemployed men were more likely to increase their labor supply or job search efforts during the Great Recession than during the mid-2000s, suggesting that macroeconomic conditions also play a role.

In general, most of the studies on the added worker effect do not account for endogeneity between the husband's unemployment status and the wife's labor supply and unobservables that are correlated with these employment variables, such as couples having similar unobserved labor market abilities due to assortative mating. ${ }^{2}$ I contribute to the literature by accounting for these effects in my search model. I correct for simultaneity by modeling the household as one decision-making unit that chooses both the husband's and the wife's labor supply rather than having each spouse decide on his or her own labor supply separately. I account for unobservables by incorporating unobserved heterogeneity into various parts of my model such that the

\footnotetext{
${ }^{2}$ For instance, more talented men, who might be less likely to become unemployed, may marry similar women who are also talented and have greater success in the job market.
} 
identification of the parameters for these variables does not rely on strong functional form assumptions.

\subsection{Liquidity Constraints and UI Benefits}

One common finding in the unemployment and job search literature is that UI benefits increase unemployment durations (e.g. Meyer (1990) and Moffitt (1985)). However, the impact of other household characteristics, such as savings or spousal labor supply, on an individual's responsiveness to changes in UI is a topic which has not been given as much attention. Exploring the interaction between assets and UI, Chetty (2008) finds that the increase in unemployment durations due to an increase in UI benefits is much larger for liquidity-constrained individuals than for non-liquidity-constrained individuals. Chetty (2008) proxies for liquidity constraints in his hazard models with a household's liquid assets, whether the household has a mortgage, and whether the individual was in a single or dual-earner household before the unemployment spell. In a paper that combines Chetty's (2008) work on liquidity constraints and Cullen and Gruber's (2000) work on spousal labor supply and UI, Brown (2010) finds that a secondary earner's sensitivity to UI benefits is affected by liquidity constraints as well.

The statistical methodology used in both of these papers assumes that assets are exogenous. However, this assumption may be violated if highly talented individuals are able both to find a job more easily and accumulate more assets prior to a job loss. My methodology allows me to correct for the potential correlation between assets and unobservables. As discussed in section 4, I am able to account for the endogeneity in assets through both my identification strategy and incorporation of various forms of unobserved heterogeneity in my model. 


\subsection{Household Search Papers}

While the unit of analysis in most job search models is the individual, there are some papers that estimate a search model describing the behavior of married couples. Burdett and Mortensen (1977) were the first to develop a household search model. However, no additional papers have developed these types of models until very recently. To my knowledge, the only other published paper is Dey and Flinn (2008), which estimates a model in which job offers consist of both wages and possible health insurance coverage. Other household search models can be found in a small set of unpublished papers. Flabbi and Mabli (2012) construct a paper comparing estimates between household and individual search models, and Liu (2009) constructs a household search model which borrows heavily from Chiappori's (1992) static model of household labor supply. Garcia-Perez and Rendon (2012) have a work in progress which studies how employment transitions affect household consumption. In a paper that resembles a household search model, Gemici (2011) estimates a dynamic model of household migration and labor supply. Other papers, such as Guler, Guvenen, and Violante (2009) and Mankart and Oikonomou (2011), develop household search models in which the parameters are calibrated rather than estimated with maximum likelihood or similar techniques.

My work contributes to this body of research in several ways. First, I incorporate assets, UI benefits, and variation in UI receipt into a household search model. This allows me to study the effects of liquidity constraints on search behavior via analysis of non-employed couples who have both no UI benefits and no assets. To provide a plausibly exogenous shift in a household's budget set, I also incorporate state variation in maximum UI benefits and maximum UI durations. I discuss the exogeneity of these variables in section 5 .

My other primary contribution is incorporating unobserved heterogeneity into 
many parts of my model. This type of variable is not present in the household search models described above, and including such variables offer several benefits. First, they provide a framework in which I can allow for key explanatory variables, like assets or the other spouse's wage, to be correlated with unobservable characteristics. Second, they allow for functions in my model, such as the offered wage distribution, to vary across households. This variation allows me to examine research questions that would be more difficult to address otherwise, such as how changes in expectations about future wages affect spousal labor supply. ${ }^{3}$

\section{Model}

In this section, I present an infinite horizon, discrete time job search model which describes how married couples make savings and employment decisions. To simplify my model, I ignore decisions to marry, divorce, and move to another state. During every one-month period, a married couple faces the following decisions and events sequentially. First, each spouse receives one job offer with a known non-zero probability. These offers can be for either full-time or part-time work, and both employed and non-employed spouses can receive job offers. ${ }^{4}$ Second, the household decides whether to accept any job offers and how much to save and consume with full knowledge of the characteristics of each job offer. Households receive labor income and unemployment benefits at the time of this decision. Third, employed spouses either keep or lose their jobs with an exogenous probability. ${ }^{5}$ Fourth, job-losers are then eligible for and take up UI during the following month with a combined exogenous probability. Figure 5 displays a flow chart visually depicting the sequence of events

\footnotetext{
${ }^{3}$ In my model, changes in the mean of a spouse's wage distribution, which is a function of unobserved heterogeneity, can be seen as a change in a household's expectation about future wages.

${ }^{4} \mathrm{My}$ non-employment status includes spouses who are either unemployed or not in the labor force. I discuss in section 5 why I do not make use of job search information available in the SIPP.

${ }^{5}$ In other words, job terminations in my model are never voluntary. I make this simplification because I cannot clearly distinguish between voluntary and involuntary job terminations for many households in my data.
} 
for a household surveyed in the SIPP.

\subsection{Arrival of Job Offers}

At the beginning of period $t$, each spouse $p \in\{m, f\}$ obtains one job offer with probability $\lambda_{p}(\cdot)$ that is a function of local economic conditions, spousal employment, and demographic variables. ${ }^{6}$ I assume that this probability is a function of the unemployment rate in the household's state of residence $s$, denoted by $R_{s, t}$. The dependence of $\lambda_{p}(\cdot)$ on $R_{s, t}$ captures how the economic conditions in a state $s$ affect the ease of finding a job. I also assume that $\lambda_{p}(\cdot)$ differs for spouses who are employed versus not employed. This distinction is captured by the indicator $1\left\{H_{p, t}=0\right\}$, in which the variable $H_{p, t}$ represents the number of hours a spouse works at the beginning of time $t$. The variable $H_{p, t}$ can equal one of three values: 0 for spouses without a job, $P T$ for part-time jobs, and FT for full-time jobs. To account for potential duration dependence, I also allow the probability of finding a job to be a function of the number of months a spouse has been without a job. I use the variable $L_{p, t}$ to denote the number of months a spouse has been without a job or working for his or her current employer. ${ }^{7}$ Finally, I let demographic characteristics for spouse $p$, denoted by $X_{p}$, affect the probability of receiving a job offer. The vector $X_{p}$ includes a spouse's age when first interviewed, race, and education levels, which I assume do not change across time. ${ }^{8}$ Formally, $\lambda_{p}(\cdot)$ is a function of the vector $\left(R_{s, t}, 1\left\{H_{p, t}=0\right\}, L_{p, t}, X_{p}\right)$.

If a spouse receives a job offer, the offer is for part-time work with probability $\pi_{p}^{P T}$ and is for full-time work with probability $1-\pi_{p}^{P T}$. The offered wage $W_{p, t}^{\prime}$ is drawn from the density $g_{w, p}\left(W_{p, t}^{\prime} \mid H_{p, t}^{\prime}, R_{s, t}, X_{p}, \nu_{w, p}\right)$ that is a function of the offered hours wage $H_{p, t}^{\prime}$, the state unemployment rate $R_{s, t}$, spousal demographics $X_{p}$, and a timeinvariant unobserved variable $\nu_{w, p}$. This unobserved variable represents time-invariant

\footnotetext{
${ }^{6}$ Mnemonically, $m$ stands for male, $f$ stands for female, and $p$ stand for person.

${ }^{7}$ Mnemonically, $L$ stands for length.

${ }^{8}$ While assuming spouses never age is unrealistic, this assumption simplifies my state space and should not significantly bias my results since I only observe households for a few years.
} 
unobservable characteristics which affect a spouse's distribution of wages, such as the spouse being particularly intelligent or hardworking. Job offers also contain a nonpecuniary benefit, $\mu_{p, t}^{\prime}$, which encompasses job characteristics such as a pleasant work environment. ${ }^{9}$ This benefit is independent of the offered wage and hours worked and is drawn from the density $g_{\mu}\left(\mu_{p, t}^{\prime}\right){ }^{10}$

\subsection{Acceptance and Savings Choice}

After each spouse has the opportunity to receive a job offer, the couple decides as a unit whether to accept these offers and how much to save this month based on the utility flow and budget constraints associated with each choice. If both spouses receive a new job offer, their choices with respect to the job offers are: (1) both accept the offers; (2) husband accepts, wife rejects; (3) husband rejects, wife accepts; or $(4)$ both reject. I use the indicator $D_{p, t}$ to denote the acceptance choice of spouse $p$, in which the variable $D_{p, t}=1$ if spouse $p$ accepts a new job offer at time $t, 0$ otherwise. ${ }^{11} \widetilde{W}_{p, t}\left(D_{p, t}\right), \widetilde{H}_{p, t}\left(D_{p, t}\right)$, and $\widetilde{\mu}_{p, t}\left(D_{p, t}\right)$ denote the wage, hours worked, and non-pecuniary benefit chosen by a spouse at time $t$, in which $\widetilde{W}_{p, t}(0)=W_{p, t}$ if the spouse keeps his or her current job and $\widetilde{W}_{p, t}(1)=W_{p, t}^{\prime}$ if the spouse accepts the new job offer. ${ }^{12}$ The size of the household's choice set decreases when only one or neither spouse receives a job offer.

\subsubsection{Utility Flow}

The utility a household receives from each choice depends upon contemporaneous utility flows as well as the household's expectation about future utility flows. The household's contemporaneous utility flow is composed of the following parts: a func-

\footnotetext{
${ }^{9}$ I include this variable to allow for spouses to accept and keep a job which pays a lower wage.

${ }^{10} \mathrm{I}$ assume independence because I cannot separately identify the variance of $\mu_{p, t}^{\prime}$ from the covariance between $\mu_{p, t}^{\prime}$ and $W_{p, t}^{\prime}$.

${ }^{11}$ If spouse $p$ did not receive a job offer, then $D_{p, t}=0$

${ }^{12}$ To help further clarify the distinction between the three wage variables, $W_{p, t}$ is the wage the spouse has at the start of the month, $W_{p, t}^{\prime}$ is the wage for the job offer the spouse possibly receives, and $\widetilde{W}_{p, t}\left(D_{p, t}\right)$ is the wage the spouse has once the household has made the job acceptance decision.
} 
tion of household consumption $C_{t}$, a function of each spouse's leisure, each spouse's non-pecuniary benefit $\tilde{\mu}_{p, t}\left(D_{p, t}\right)$, and a time-choice-specific shock $\epsilon_{t}\left(D_{m, t}, D_{f, t}\right)$. The consumption function encompasses how much a household values consumption as well as how risk-averse a household is. The time-choice-specific shocks are unknown to the household until right after job offers arrive, but the distribution is always known. ${ }^{13}$ Based on this setup, the household's utility function is

$$
\begin{array}{r}
\overbrace{f_{C}\left(C_{t} \mid X_{t}\right)}^{\text {consumption }}+\overbrace{f_{L}\left(\widetilde{H}_{m, t}\left(D_{m, t}\right), \widetilde{H}_{f, t}\left(D_{f, t}\right) \mid X_{t}\right)}^{\text {leisure }}+ \\
\underbrace{\tilde{\mu}_{m, t}\left(D_{m, t}\right)+\tilde{\mu}_{f, t}\left(D_{f, t}\right)}_{\text {non-pecuniary benefits }}+\underbrace{\epsilon_{t}\left(D_{m, t}, D_{f, t}\right)}_{\text {utility shocks }}
\end{array}
$$

\subsubsection{Budget Constraint}

In this utility function, each spouse's income and the household's current assets $A_{t}$ constrain the household's level of consumption $C_{t}$. Employed spouses receive labor income $\widetilde{W}_{p, t}\left(D_{p, t}\right) \widetilde{H}_{p, t}\left(D_{p, t}\right)$, and non-employed spouses may receive unemployment benefits $B_{p, t} \cdot{ }^{14}$ The latter variable is a state-specific function of a spouse's previous wage and may be zero if a spouse did not qualify for UI benefits or has exceeded the maximum duration of benefits. After interest is incorporated, the difference between consumption and the sum of income and current assets is the household's level of assets $A_{t+1}$ for the following month. $A_{t+1}$ is bounded from below by a minimum amount $\varpi .{ }^{15}$ Given these conditions, when the household's current level of assets $A_{t}$ is greater than $\varpi$, the budget constraint is

\footnotetext{
${ }^{13}$ While these shocks are written as functions of the accept or reject decision, these variables can also reflect utility shocks from a spouse's current and offered jobs.

${ }^{14}$ I pick the values for hours worked $P T$ and $F T$ such that the product of hourly wage and hours worked equals monthly labor income.

${ }^{15}$ I set this parameter to 1 to not allow borrowing and to avoid any computational problems arising from consumption or assets being too close to zero.
} 


$$
\begin{array}{r}
\frac{A_{t+1}}{1+\iota}+C_{t} \leq \overbrace{\widetilde{W}_{m, t}\left(D_{m, t}\right) \widetilde{H}_{m, t}\left(D_{m, t}\right)+\widetilde{W}_{f, t}\left(D_{f, t}\right) \widetilde{H}_{f, t}\left(D_{f, t}\right)}^{\text {Labor income }}+ \\
\underbrace{1\left(\widetilde{H}_{m, t}\left(D_{m, t}\right)=0\right) B_{m, t}+1\left(\widetilde{H}_{f, t}\left(D_{f, t}\right)=0\right) B_{f, t}}_{\text {UI income }}+A_{t} \\
\underbrace{\varpi}_{\text {Borrowing Constraint }} \leq A_{t+1},
\end{array}
$$

in which $\iota$ is the interest rate and $\frac{A_{t+1}}{1+\iota}$ is the level of assets before interest is added. If the household's level of assets falls to $\varpi$ and the household has no income in a month, the household receives an undesirable minimum consumption amount $C_{\min }$ and the household's assets remain at $\varpi$.

\subsection{Birth, Job Loss, and UI Receipt}

After the acceptance and savings choices are made, the wife gives birth to a new child with an exogenous probability $\chi\left(X_{f, t}\right)$ that is a function of the wife's age, number of children in the household, and the age of the youngest child in the household. A birth can both alter the wife's preference for leisure and affect the probability of the wife's job ending. I incorporate births to account for spouses leaving the workforce when a baby is born, but in order to simplify my model, I do not make fertility a choice variable. After the potential birth, spouses face the possibility of their jobs ending, which can be due to either an involuntary termination or a spouse quiting his or her job. Spouses lose their jobs with an exogenous probability $\eta_{p}\left(L_{p, t}, R_{s, t}, X_{t}^{\prime}, \nu_{\eta, p}\right)$ and keep their jobs with probability $1-\eta_{p}(\cdot)$, in which $X_{t}^{\prime}$ is the value of the demographic variables after a potential birth. I do not allow quitting to be an endogenous choice because I cannot clearly distinguish between voluntary and involuntary quits for many

spouses in my dataset. I let $\eta_{p}(\cdot)$ be a function of the duration variable $L_{p, t}$ to allow spouses to be more likely to keep their job if they have been with their employer 
for a longer period of time. The dependence of $\eta_{p}(\cdot)$ on the unemployment rate $R_{s, t}$ captures how economic downturns affect the probability of losing a job. I include $X_{t}^{\prime}$ because observable characteristics, such as age or education, should affect the probability of a spouse being fired or laid off. I also allow $\eta_{p}(\cdot)$ to be a function of whether the wife just gave birth to account for women and men who leave their jobs following a birth in the household. $\nu_{\eta, p}$ represents time-invariant unobservable characteristics, such as insubordination, that could affect the probability that a spouse loses a job.

Job losers are able to receive UI benefits during the following month with probability $\psi_{p}\left(L_{t}, X_{t}^{\prime}\right)$, which captures the likelihood of both eligibility and take-up. This probability needs to be included since spouses are eligible for unemployment insurance if they are laid off but not if they are fired for certain reasons and because take-up of UI is incomplete. I include the current length of employment at the spouse's current job in this probability because an individual typically needs to work more than one calendar quarter to qualify for UI.

\subsection{Evolution of Unemployment Rates and UI Benefits}

In the next month, a spouse who received UI benefits at time $t$ is eligible for UI at time $t+1$ only if the number of months a spouse has been receiving UI is less than the maximum number of months a spouse can receive UI benefits in state $s$. I assume for simplicity that households believe the UI maximum duration will never change even though these state maximums do change in my data. For spouses who lose a job at time $t$ and are eligible for UI, the value of their UI benefits $B_{p, t+1}$ in the next period is a function of their total labor income at time $t$ as well as the replacement rate and the maximum benefit amount for the state in which the household currently resides in. ${ }^{16}$

\footnotetext{
${ }^{16}$ While the actual construction of UI benefits is more complicated, the simplification I use is a good approximation of UI benefits and help me reduce the size of my state space.
} 
The household assumes that the state unemployment rates follow a $\mathrm{AR}(1)$ process. ${ }^{17}$

\subsection{Value Function}

The dynamic decision-making process for the household is encompassed by a value function $V\left(S_{t}\right)$ that depends on my vector of state variables $S_{t}$. To simplify my notation, I let the vector $J_{t}^{\prime}$ contain the job-offer-related variables $W_{p, t}^{\prime}, H_{p, t}^{\prime}$ and $\mu_{p, t}^{\prime}$; $D_{t}=\left(D_{m, t}, D_{f, t}\right)$; and Income $_{t}\left(D_{t}\right)$ denote the income that is available to the household for every accept or reject choice $D_{t}$. After this modification, the value function for the household is

$$
\begin{gathered}
V\left(S_{t}\right)=\max _{C_{t}, D_{t}} U\left(S_{t}, C_{t}, D_{t}, J_{t}^{\prime}, \epsilon_{t}\right)+\beta E\left[V\left(S_{t+1}\right) \mid C_{t}, D_{t}, J_{t}^{\prime}, S_{t}\right] \\
\text { subject to } \\
0<C_{t} \\
C_{t}+\frac{A_{t+1}}{1+\iota} \leq A_{t}+\text { Income }_{t}\left(D_{t}\right) \\
\varpi
\end{gathered}
$$

in which the expectation is with respect to the job variables $J_{t+1}^{\prime}$, utility shocks $\epsilon_{t}$, whether a spouse will lose his or her job, whether a job-loser will be eligible for and take up benefits, the state and national unemployment rates, the birth of a child, and the maximum duration of unemployment benefits.

\section{Identification}

One goal of this paper is to estimate the model described in section 3 using data from the SIPP. In order to properly perform my estimation exercise, I need to

\footnotetext{
${ }^{17}$ The replacement rates and maximum benefit amounts change very little over time, so I treat these variables as time-invariant.
} 
establish how my model is identified based on features of this dataset. In the rest of this section, I discuss how the functions of interest in my model (such as the job offer probability, the offered wage distribution, the utility function, and the job loss probability) are separately identified from one another based on exclusion restrictions and certain correlations I observe in the data. At the end of this section, I discuss how the identification of the parameters in my model allows me to account for the endogeneity in savings, spousal labor supply, and UI benefits.

\subsection{Utility Function and Wage Distribution Parameters}

First, I discuss how the parameters for the observed and unobserved variables in the utility function and the wage distribution are identified. Due to the presence of unobserved heterogeneity, I have a selection problem in which higher skilled spouses and partners of higher skilled spouses are more likely to be employed, a factor which could potentially bias my estimates of the wage distribution and other parameters. To address this identification problem, I propose a line of reasoning which resembles the identification arguments for a Heckman selection model. In a Heckman selection model, the wage equation is nonparametrically identified if one variable in the selection equation is excluded from the wage equation. A fairly common exclusion restriction made when estimating a Heckman selection model for the wages and labor force participation of women, for instance, is to include variables involving children only in the selection equation for labor force participation. In my structural model, I make a similar exclusion restriction by having children affect the utility function but not the wage distribution. Also, to help separately identify the utility function from other functions in my model, I let the state unemployment rate affect the wage distribution but not the utility function. These exclusion restrictions reduce the reliance on functional form assumptions for identifying the parameters in the wage distribution 
and utility function. ${ }^{18}$

Certain correlations in wages that I observe in the dataset also help identify the parameters for unobserved heterogeneity in the wage distribution. The persistence in wages for spouses who change jobs over time, after controlling for observable characteristics, identifies the variances of the unobserved heterogeneity in wages for both the husband and the wife. For example, if there are many spouses who have persistently high wages across different jobs and many other spouses who have persistently low wages across different jobs, then these variances will be high. Less persistence in wages across jobs implies that these variances will be lower. The correlation in wages between spouses after controlling for observable characteristics identifies the correlation between the husband's and the wife's unobserved heterogeneity in wages. Also, the plausibly exogenous variation in UI generosity across states discussed in Section 5 provides an exogenous shift in a household's budget constraint, which allows me to obtain more precise estimates of the utility function.

\subsection{Job Offer and Job Loss Probability Parameters}

Next, I discuss identification for parameters associated with the job offer and job loss probabilities. First, note that the job offer probability and the wage distribution are not separately identified nonparametrically because I do not observe the job offers that are rejected. Because of this, I cannot distinguish between a spouse not receiving a job offer and a spouse receiving a job offer that he or she rejects. However, these functions are separately identified parametrically. Therefore, given a functional form of the wage distribution, the parameters in the job offer probability are identified by the degree to which they help the model better predict the prevalence of new jobs

\footnotetext{
${ }^{18}$ To recover all the parameters in the wage distribution, I also need to use certain parametric forms for the wage distribution. Flinn and Heckman (1982) discuss that in a search model, all the parameters in the wage distribution can be identified from the observed distribution of wages if the $\log$ normal distribution is used but not if the Pareto distribution is used. This problem arises from the inability to observe wage offers in the lower tail of the wage distribution that are always rejected.
} 
being started. For example, if spouses employed full-time rarely switch jobs even though the wage distribution implies that there is a high probability of a spouse receiving a higher paying job if a job offer is received, then the job offer probability will be low. However, since the estimates of this probability are sensitive to functional form assumptions, this probability should be seen as another function associated with the wage distribution which helps the model predict how often job offers are accepted or rejected rather than as a function that generates the true probability of receiving a job offer.

Another identification problem I face pertaining to the job offer and job loss probabilities is the difficulty of separately identifying the effects of unobserved heterogeneity from duration dependence, because both factors can account for the observed decreasing hazard out of unemployment over time. My line of reasoning for the separate identification of these two effects resembles the identification arguments for a proportional hazards model. Elbers and Ridder (1982) show that variation in explanatory variables and the general structure of proportional hazards models provide enough restrictions on the shape of the observed hazard to separately identify the effects of duration dependence and unobserved heterogeneity. ${ }^{19}$ While the mathematical result in Elbers and Ridder (1982) is specific to proportional hazard models, these models are similar enough to search models to imply that the general structure of search models imposes enough restrictions on the observed hazards out of employment or into employment to allow for separate identification of the effects of duration dependence, unobserved heterogeneity, and observed variables in the job offer and job loss probability without requiring strong functional form assumptions. ${ }^{20}$

\footnotetext{
${ }^{19}$ For example, these models predict that the observed hazard is multiplicative with respect to the explanatory variables and duration length if there is no unobserved heterogeneity but is nonmultiplicative if unobserved heterogeneity is present. Therefore, the degree to which the observed hazard is non-multiplicative helps identify the effects of unobserved heterogeneity (Van den Berg, 2001).

${ }^{20}$ However, I make use of functional form assumptions to facilitate estimation of my model.
} 
Additional features of my model and data also help identify the distribution of unobserved heterogeneity in the job offer and job loss probabilities. First, Elbers and Ridder (1982) note that large variation in explanatory variables which have a strong influence on the hazard rate can yield more precise estimates of the distribution of unobserved heterogeneity in a proportional hazards model. This suggests that the large variation in the unemployment rate between 2004 and 2013, my time period of interest, may allow me to obtain more precise estimates of the distribution of unobserved heterogeneity in my search model. Second, I observed some spouses who are unemployed multiple times during the course of the panel. Because the observed heterogeneity in my model does not change across unemployment spells, this multi-spell data provides additional information which helps me distinguish between the effects of unobserved heterogeneity and duration dependence. ${ }^{21}$ Third, the correlation of employment and non-employment durations between spouses can help me distinguish between the effects of state dependence and the effects of unobserved heterogeneity. In my model, I assume that the length of time one spouse is unemployed does not directly affect the probability the other spouse will receive a job offer, but I do allow the unobserved heterogeneity affecting these probabilities potentially to be correlated between spouses. As a result of this restriction, if I observe a correlation in the length of time spouses are unemployed, then this would suggest that the observed duration dependence is due to the effects of unobserved heterogeneity rather than state dependence.

\subsection{Correcting for Endogeneity of Key Variables}

To conclude this section, I describe how my model and identification strategy allow me to account for the endogeneity in savings, spousal labor supply, and UI benefits. One way I control for potential endogeneity problems is by modeling how

\footnotetext{
${ }^{21}$ Honoré (1993) shows that multi-spell data allow for proportional hazard models to be identified under less-restrictive assumptions.
} 
my key variables correlate with unobservables. For example, I describe how assets are indirectly correlated with unobserved labor market abilities by incorporating unobserved heterogeneity into my wage distribution and job loss probability. In my model, if spouses have high values for their wage unobserved heterogeneity and low values for their job loss unobserved heterogeneity, then such spouses are more likely to keep and retain jobs with high wages, allowing their households to accumulate greater assets. This example illustrates how I am able to address numerous potential endogeneity problems through the incorporation of unobserved heterogeneity into my model. However, in order to properly use my model to correct for endogeneity, the underlying parameters in the model need to be identified properly. Earlier in this section, I discuss how my parameters are identified based on exclusion restrictions and certain correlations I observe in the data. Therefore, the combination of both my identification strategy and the incorporation of various forms of unobserved heterogeneity in my model allows me to account for the endogeneity in my variables of interest.

\section{Data}

To estimate my model, I use the 2004 and 2008 Panels of the Survey of Income and Program Participation (SIPP). The SIPP collects information about the income, labor market activity, and participation in government welfare programs of U.S. households. This dataset is well-suited for my project because it includes a large number of married couples, contains high-frequency employment data, and has data on UI receipt. In the SIPP, households are interviewed about their monthly activities every four months for a period of about four years. Together, the panels cover the years between 2004 and 2013. I make use of both the 2004 and 2008 panels so I can compare household behavior before and after the start of the Great Recession, allowing me to explore the effects of macroeconomic conditions on household behavior. 
Because I model only the employment decisions of working-aged married couples, I make several sample-selection restrictions. First, I limit my sample to married opposite sex couples in which both spouses are between the ages of 21 and $61 .^{22}$ Second, I exclude households with spouses who are in school, disabled, retired, or own a business sometime during the course of the panel. ${ }^{23}$ Third, I drop married couples that divorce during the panel, have key employment or UI data imputed, move to a different state, or that miss an interview but then rejoin the panel. After imposing these restrictions, I am left with 9,622 households in total. I discuss my sample selection criteria as as some other data issues in more detail in appendix A.1

\subsection{Summary Statistics}

Table 1 presents summary statistics for the variables I use in my model. My employment variables of interest are as follows: a discrete variable for being employed, hours worked, hourly wage, UI benefits, and length of time either employed or not employed. The average hourly wage for my sample, conditional on employment, is about $\$ 23$, and the average weekly UI benefit, conditional on receipt, is approximately $\$ 302 .{ }^{24}$ While I have information on labor force status at the weekly level, I use a month as my unit of time since the other key variables in the SIPP are updated only monthly. I do not make use of the job search information in the SIPP for my project because these data do not have information on search intensity or on-the-job search.

To further describe my employment variables, I present sample means of selected variables in Table 2 broken down by gender and panel year. Wives on average are less likely than husbands to be employed, have lower wages, and are more likely to have part-time jobs if they are working. For example, the employment rate and averages

\footnotetext{
${ }^{22}$ I drop spouses after age 62 because that is the age at which individuals can start collecting Social Security benefits. I also drop couples under the age of 21 to excluded college-aged individuals.

${ }^{23}$ I exclude couples who own a business because the decision to start a business may be very different from the decision to work for a new employer.

${ }^{24}$ Both variables are measured in 2010 dollars.
} 
Table 1: Summary Statistics

\begin{tabular}{lcc} 
& Mean & Std Dev \\
\hline Employed & 0.85 & 0.36 \\
Working Part-time (Given Employed) & 0.12 & 0.32 \\
Hourly Wage (Given Employed) & $\$ 23.37$ & $\$ 14.92$ \\
Receiving UI Benefits (Given not Employed) & 0.12 & 0.32 \\
Monthly UI Benefits (Given Receipt) & $\$ 301.65$ & $\$ 156.58$ \\
Months Employed (Given Employed) & 38.57 & 15.34 \\
Months Non-employed (Given not Employed) & 29.04 & 19.76 \\
& & \\
Age & 40.20 & 9.22 \\
White & 0.75 & 0.43 \\
High School & 0.22 & 0.42 \\
Some College & 0.34 & 0.47 \\
College & 0.35 & 0.48 \\
Number of Children Under 18 & 1.34 & 1.21 \\
Age of Youngest Child (Given have a Child) & 8.02 & 5.63 \\
Liquid Assets & $\$ 113,382$ & $\$ 152,703$ \\
Number of Months in Sample & 36.43 & 15.75 \\
Number of Households & 9,622 & \\
\hline
\end{tabular}

Data from the 2004 and 2008 panels of the Survey of Income and Program Participation. My sample consists of married opposite-sex couples who do not divorce during the course of the panel in which both spouses are between the ages of 21 and 61 and neither spouse is in school, disabled, or retired during the course of the panel. I also only include household which are in the sample for 5 months or more and do not move to a different state. Survey weights were used to construct this table. The education variables represent the highest level of education a spouse has received. Liquid wealth is defined as a household's total wealth minus their home, vehicle, and business equity. All monetary variables are measured in 2010 dollars. The unit of observation in this table is an individual-month observation.

Table 2: Employment Variables by Gender and Panel Year

\begin{tabular}{lcccc} 
& \multicolumn{2}{c}{ Husbands } & \multicolumn{2}{c}{ Wives } \\
& 2004 & 2008 & 2004 & 2008 \\
\hline Employed & 0.961 & 0.936 & 0.757 & 0.726 \\
Working Part-time (Given Employed) & 0.030 & 0.044 & 0.222 & 0.226 \\
Hourly Wage(Given Employed) & 26.0 & 26.6 & 19.1 & 20.4 \\
Receiving UI Benefits (Given Not Emp.) & 0.270 & 0.493 & 0.045 & 0.081 \\
\hline
\end{tabular}

See notes in Table 1. Displayed values are sample means by gender and panel years. 
Table 3: Markov Transition Matrices

\begin{tabular}{lcc}
\multicolumn{3}{c}{ Husband's Transitions } \\
\hline & Not Emp. (This Month) & Emp. (This Month) \\
\hline Not Emp. (Last Month) & 82.48 & 17.52 \\
Emp. (Last Month) & 0.90 & 99.10 \\
\hline
\end{tabular}

Wife's Transitions

\begin{tabular}{lcc}
\hline & Not Emp. (This Month) & Emp. (This Month) \\
\hline Not Emp. (Last Month) & 96.18 & 3.82 \\
Emp. (Last Month) & 1.27 & 98.73 \\
\hline
\end{tabular}

See notes in Table 1. Cell $i, j$ represents the probability of a spouse being in state $j$ the following month given the spouse is currently in state $i$. The cells are calculated from the simple frequencies observed in the data.

Table 4: Liquid Assets Percentiles (\$)

\begin{tabular}{cllllll}
\hline $5^{\text {th }}$ & $10^{\text {th }}$ & $25^{\text {th }}$ & $50^{\text {th }}$ & $75^{\text {th }}$ & $90^{\text {th }}$ & $95^{\text {th }}$ \\
\hline 0 & 70 & 4,986 & 43,304 & 158,410 & 367,354 & 534,229 \\
\hline
\end{tabular}

See notes in Table 1.

hourly wage for husbands in the 2008 panel is $93.6 \%$ and $\$ 26.60$, respectively, while the employment rate and average wage for wives in the same panel are $72.6 \%$ and $\$ 20.40$, respectively. UI receipt is also much lower for women, and UI receipt for both genders is higher in the 2008 Panel because a higher proportion of the non-employed population in the 2008 Panel are jobless due to layoffs. The rates of employment for husbands are higher than the national average because the rates of unemployment are lower for married men than for unmarried men in general.

I also present a table of monthly statistics on transitions between working and not working in Table 3. This table shows that husbands are much more likely to transition from not working to working than wives. Another key variable in my model is a household's liquid assets. I construct this variable using a similar definition of liquid wealth presented in Chetty (2008). ${ }^{25}$ In addition to the mean of assets presented in

\footnotetext{
${ }^{25}$ Chetty (2008) defines this variable as a household total wealth minus their unsecured debt (e.g. credit card debt) and home, vehicle, and business equity. In my definition, I do not subtract off unsecured debt because I do not allow for household to borrow money.
} 
Figure 1: Maximum Weekly UI Benefits in 2011

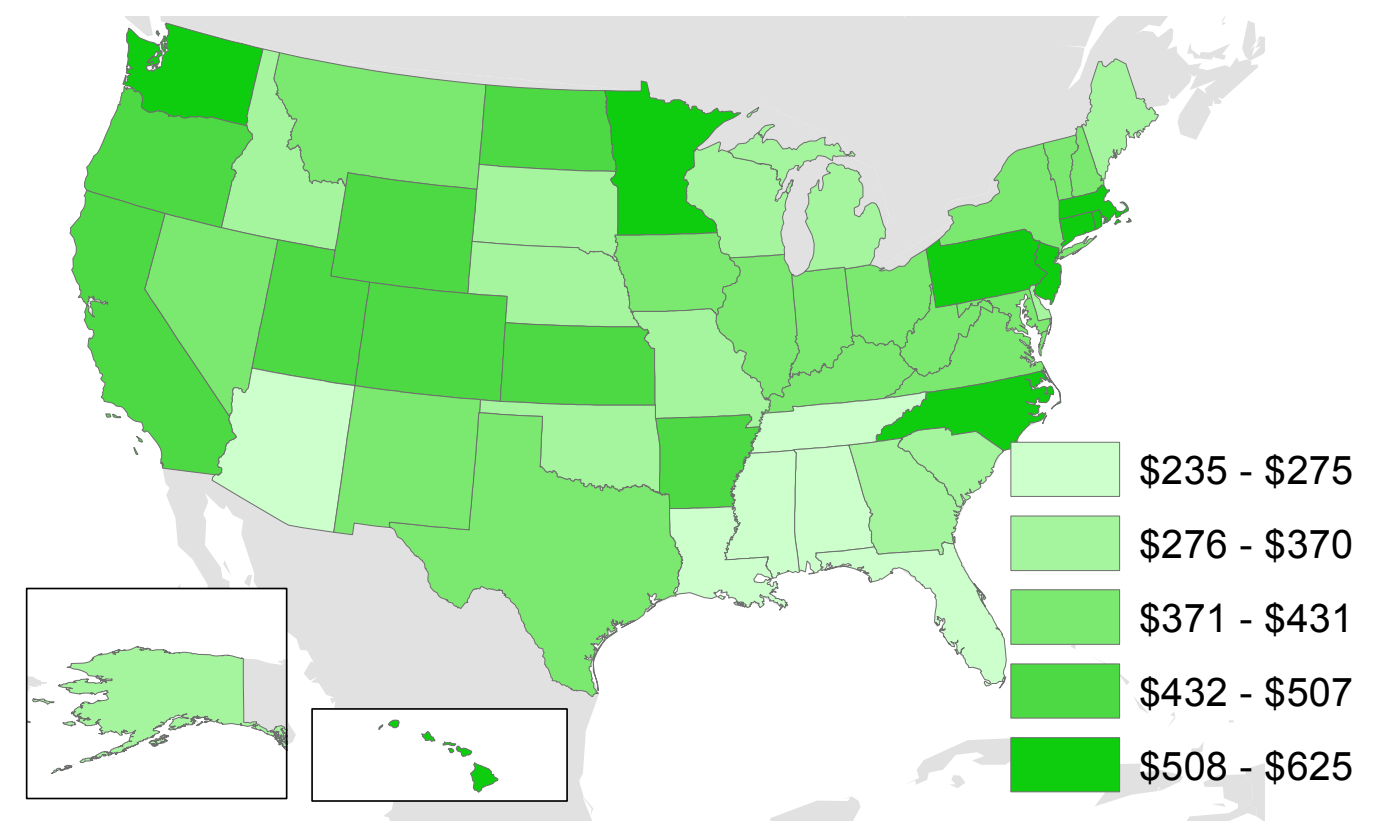

Table 1, I display percentiles of assets in Table 4. This table shows that the $10^{\text {th }}$ percentile of liquid assets is only $\$ 70$ and the $25^{\text {th }}$ percentile is approximately $\$ 5,000$, suggesting that a sizable number of household in my sample lack sufficient assets to fund a period of job search.

\subsection{Unemployment Insurance}

I also incorporate various characteristics of the U.S. Unemployment Insurance system into my dataset. ${ }^{26}$ While the exact formula for an individual's UI benefit is somewhat complicated, in general, an unemployed individual receives a fraction of his or her previous wage up to a maximum benefit amount. ${ }^{27}$ Krueger and Meyer (2002) find that around $35 \%$ of the unemployed receive the maximum benefit, so this maximum is an important feature of the UI system. The maximum benefit amounts vary significantly across states without an obvious pattern, as shown by Figure 1. For example, North Carolina in 2011 had a high maximum, but neighboring Tennessee

\footnotetext{
${ }^{26}$ I obtain information on the UI system from the U.S Department of Labor's website.

${ }^{27}$ This fraction of wages is called the replacement rates.
} 
had a low maximum. ${ }^{28}$ Because of this variability, papers which use these UI variables, such as Chetty (2008) and Krueger and Mueller (2010), assume that these variables are uncorrelated with other state characteristics which could affect labor supply. This plausible exogeneity allows me to identify the effects of a change in UI benefits on spousal labor supply.

Another important UI variable for my time frame of interest is the maximum number of weeks an individual can receive UI. Under normal economics conditions, this maximum is 26 weeks for most states. However, since the start of the Great Recession, there are two governmental programs in place which extend the maximum number of weeks to 99 in some states. The first is the Emergency Unemployment Compensation (EUC) 2008 program. This is a federal program that extends the maximum number of weeks an individual can receive UI, with the length of the extension depending on the state unemployment rate. Congress has increased the number of additional weeks provided by this program since it was first created. While the federal government increased the number of weeks as the national unemployment rate grew higher, the exact timing and number of additional weeks created by the EUC extensions appear to be random. Because of this, the creation and extension of the EUC program can be interpreted as an exogenous shock to the duration of UI benefits once the unemployment rate is controlled for. Rothstein (2012) presents similar exogeneity arguments in his paper on these UI extensions.

Another UI program is the Extended Benefit (EB) program. The mechanics of the EB program differ slightly from the EUC program, causing the EB program to provide a unique source of cross-state variation in the maximum duration of benefits. Depending on state economic conditions, this program increases the maximum number of benefit weeks by an additional 13 or 20 weeks beyond what the EUC program

\footnotetext{
${ }^{28}$ These maxima change very little over time with the exception of North Carolina, which substantially lowered its maximum on July 2013.
} 
Figure 2: Timeline of Adoption of Optional EB Trigger

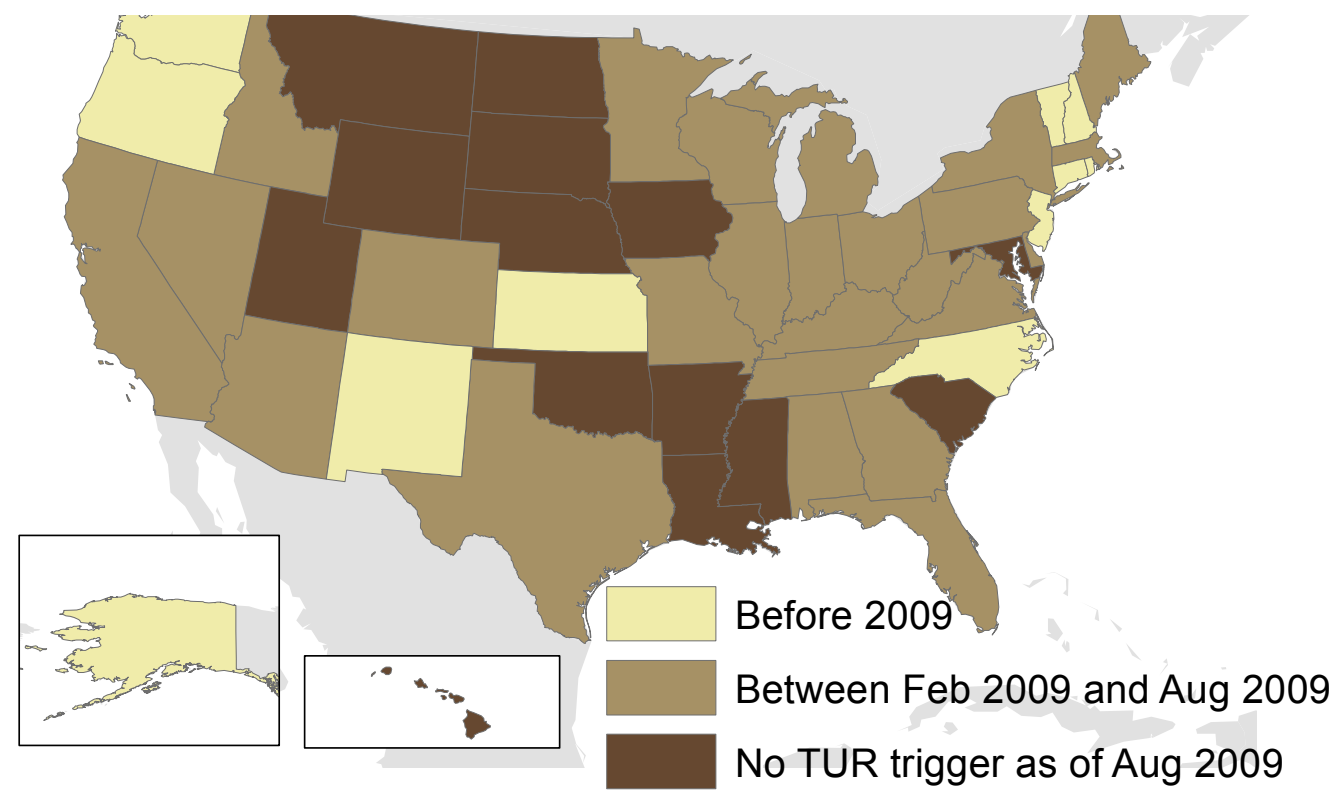

provides. This increase is more likely to happen if a state adopts an optional trigger, which many states adopted after the federal government took on more responsibility for funding this program in the American Recovery and Reinvestment Act (ARRA) of 2009. This optional trigger is based on a state's total unemployment rate (TUR) and the default trigger is based on the state's insured unemployment rate (IUR). Due to the peculiarities of the law, the threshold based on the TUR is more likely to be passed than the threshold for the IUR. Figure 2 displays which states adopted the trigger after the ARRA was passed in February of 2009 and which states had not done so as of August 2009. ${ }^{29}$ The existence of this optional trigger in the EB program allows for states with the same unemployment rate to have potentially different maximum durations of UI benefits. While there does seem to be some clustering of adoption along state geographic or political lines, overall, there does not appear to be a coherent pattern as to which states adopted this trigger, and if they did, when they did so. Because of this haphazard adoption pattern which appears to be unrelated

\footnotetext{
${ }^{29}$ Most states that adopted the optional trigger did so by August of 2009.
} 
to other state characteristics, the Extended Benefit program can be used as another plausibly exogenous source of variation in UI benefit durations.

\subsection{Descriptive Probit Model}

To conclude this section, I present evidence from my data that married couples have interdependent labor supply. I do this by estimating a probit which presents the variables that are associated with a spouse transitioning from not working to working. The benefit of using this probit model to show interdependence is that the model allows me to control for other factors, such as the unemployment rate, which might affect the labor supply of both spouses. Table 5 presents estimates of this probit model for husbands and wives. In these spousal models, the key right-hand-side variables are whether the other spouse is employed and whether the spouse in question is receiving UI benefits. Other right-hand-side variables are the number of months a spouse has been without work, the state unemployment rate, and demographic variables. The sign and significance of the variables "Other Spouse Employed" and "UI Receipt" from Table 6 show that a non-employed husband is less likely to transition to employment if his wife is working and that a husband is less likely to start working if he is receiving UI benefits, but that there is no significant effect for wives who are not employed. Other variables that have an influence on the transition probabilities are the state unemployment rate and the length of time without a job.

To make the coefficient for spousal employment from Table 5 more interpretable, I present the average marginal effects for this variable in Table 6 . The results of this table show that a wife being employed is associated with an approximately $14 \%$ decrease in the probability that the husband will be working the following month, although the analogous estimates for wives are not statistically significant. Overall, my results from Tables 5 and 6 provide some evidence that husbands and wives have interdependent labor supply and that spousal income might provide a form 
Table 5: Probit Estimates of Transition Probabilities

Outcome: A Non-Employed Spouse Starts Working the Following Month

\begin{tabular}{lll} 
& Husband & Wife \\
\hline Partner Employed & $-0.134^{* * *}$ & -0.0546 \\
UI Receipt & $(0.0477)$ & $(0.0568)$ \\
& $-0.377^{* * *}$ & -0.114 \\
Interaction Partner Employed and UI Receipt & $(0.0534)$ & $(0.103)$ \\
& $(0.054$ & 0.143 \\
Months without Work & $-0.0473^{* * *}$ & $-0.111)$ \\
Age & $(0.00263)$ & $(0.000895)$ \\
White & -0.00379 & -0.000163 \\
& $(0.00345)$ & $(0.00205)$ \\
High School & $0.133^{* * *}$ & $0.0760^{* *}$ \\
Some College & $(0.0485)$ & $(0.0332)$ \\
College & 0.0645 & $0.0843^{*}$ \\
Number of Children & $(0.0523)$ & $(0.0491)$ \\
Age of Youngest Child & 0.0404 & $0.180^{* * *}$ \\
Seam Effect Dummy & $(0.0541)$ & $(0.0462)$ \\
State Unemployment Rate & $0.131^{*}$ & $0.110^{* *}$ \\
Constant & $(0.0731)$ & $(0.0446)$ \\
& $0.0501^{* * *}$ & $0.0707^{* * *}$ \\
Observations & $(0.0177)$ & $(0.0130)$ \\
& 0.00417 & $0.0207^{* * *}$ \\
& $(0.00571)$ & $(0.00341)$ \\
& $0.568^{* * *}$ & $0.372^{* * *}$ \\
& $(0.0423)$ & $(0.0258)$ \\
& $-0.0338^{* * *}$ & $-0.0276^{* * *}$ \\
& $(0.00793)$ & $(0.00504)$ \\
& $-0.384^{* * *}$ & $-1.414^{* * *}$ \\
& $(0.112)$ & $(0.0839)$ \\
\hline & 11492 & 71474 \\
& &
\end{tabular}

The sample for this table is the same as in Table 1 but only contains spouses who are currently not working. The dependent variable is whether the spouse is working in month $t+1$. The right-handside variables are for time $t$. The variables listed are for the husband in the first column of estimates and for the wife in the second column (e.g. "UI Receipt" for the "Husband" column is for whether the husband is receiving UI). Survey weights used to construct estimates. "Age of Youngest Child" equals zero if there are no children in the household. The seam effect dummy is described in section 6.6. The standard errors displayed in parentheses are clustered at the state level. The significance asterisks for the $\mathrm{p}$-values are: ${ }^{* * *} \mathrm{p}<0.01,{ }^{* *} \mathrm{p}<0.05,{ }^{*} \mathrm{p}<0.1$. 
Table 6: Average Marginal Effects for Probit Estimates in Table 5

\begin{tabular}{lcc} 
& Husband & Wife \\
\hline Average Marginal Effect: & $-0.025^{* *}$ & -0.0023 \\
Other Spouse Employed & $(0.009)$ & $(0.0034)$ \\
Relative Change in Probabilities & $-14.3 \%$ & $-3.8 \%$ \\
\hline
\end{tabular}

This table presents estimates of the average marginal effects for the probit estimates in Table 5 . The displayed values in the first row represent the change in the probability that a non-employed spouse starts working the following month due to the other spouse being employed. Relative change in probabilities is the average marginal effect divided by the respective transition probability reported in Table 3.

of insurance that allows an individual to search longer for a job. In my structural model, I do more work to correct for potential endogeneity issues that could affect the relationship between a husband's and a wife's labor supply.

\section{Estimation and Computation}

Three types of problems frequently arise when estimating structural dynamic discrete choice models. First, many of the algorithms used to estimate these models require evaluating the value function for each trial guess of the parameters. This is problematic because solving for the value function can be very time consuming, particularly for infinite-horizon models such as mine. Second, many of these models, including my own, contain numerous unobserved variables which need to be integrated out in order to evaluate the objective function. These integrals can be difficult to evaluate because they often do not have analytical solutions. ${ }^{30}$ Third, the objective functions used to estimate these models, such as a likelihood function, are generally not globally concave (or convex), which can make finding the global extremum of these objective functions difficult (Aguirregabiria and Mira, 2010).

To address these problems, I use a modified version of the Bayesian Markov chain Monte Carlo (MCMC) algorithm developed by Imai, Jain, and Ching (2009). This

\footnotetext{
${ }^{30}$ While there exists several numerical and simulation algorithms for evaluating multidimensional integrals without analytical solutions, these algorithm frequently involve some trade-offs between speed and accuracy which can complicate estimation of a model.
} 
algorithm reduces the computational burden from evaluating the value function and is theoretically guaranteed to find the global maximum of the likelihood function. ${ }^{31}$ The enhancements I make to this algorithm allow me to handle the sizable number of state variables in my model. I also make use of data augmentation which reduces the burden of integrating out unobserved variables and makes my objective function easier to evaluate. In the rest of this section, I give an overview of Bayesian statistics, the IJC (2009) approximation of the value function, and my modifications to the IJC (2009) algorithm. I also describe the functional form assumptions I make and discuss how I incorporate data augmentation. In appendix A.2, I discuss some aspects of my algorithm in more detail.

\subsection{Bayesian Statistics}

Bayesian methods yield a distribution of parameters called the posterior distribution, which is a function of the likelihood and represents a researcher's beliefs about the parameters in the model after seeing the data. While this output is seemingly very different from the point estimates and confidence intervals generated by MLE or GMM, the mean and standard deviation of the posterior distribution are asymptotically equivalent to the MLE parameter estimates and standard errors, respectively, under mild regularity conditions (Geweke, 2005). I estimate the posterior distribution for my model using two popular and versatile Markov chain Monte Carlo (MCMC) algorithms: the Metropolis-Hastings algorithm and Gibbs sampling. These MCMC algorithms estimate the posterior distribution by generating a series of parameters $\left\{\theta^{k}\right\}_{k=1}^{K}$ which converge to the posterior distribution.

In the Metropolis-Hastings algorithm, new parameters in the series $\left\{\theta^{k}\right\}_{k=1}^{K}$ are chosen based on evaluations of the likelihood $\mathscr{L}\left(Y \mid \theta, E V\left(S_{t}, \theta\right)\right)$, in which $Y$ repre-

\footnotetext{
${ }^{31}$ Or more accurately, this algorithm converges to the posterior distribution which can then be used to find the global maximum of the likelihood function if the sample size is large or the prior is non-informative.
} 
sents observed outcomes and $E V(\cdot)$ represents the expectation of the value function. At each iteration $k, \theta^{k}$ is set equal to a random candidate parameter $\theta^{* k}$ with probability

$$
\mathscr{M}\left(\theta^{k-1}, \theta^{* k}\right)=\min \left\{\frac{\mathscr{L}\left(Y \mid \theta^{* k}, E V\left(S_{t}, \theta^{* k}\right)\right)}{\mathscr{L}\left(Y \mid \theta^{k-1}, E V\left(S_{t}, \theta^{k-1}\right)\right)}, 1\right\}
$$

and $\theta^{k}$ is set equal to $\theta^{k-1}$ with probability $1-\mathscr{M}\left(\theta^{k-1}, \theta^{* k}\right) \cdot{ }^{32}$ The candidate parameter $\theta^{* k}$ can be drawn from any density that is continuously differentiable and spans the parameter space. ${ }^{33}$ Setting $\theta^{k}=\theta^{* k}$ is called accepting $\theta^{* k}$ and setting $\theta^{k}=\theta^{k-1}$ is called rejecting $\theta^{* k}$. With this probability, if $\theta^{* k}$ results in a higher likelihood relative to $\theta^{k-1}$, then $\theta^{* k}$ is always accepted, but if $\theta^{* k}$ decreases the likelihood, then it is accepted with a probability less than one. Accepting parameters that can potentially decrease the likelihood helps prevent this algorithm from staying near a local maximum of the likelihood function that is not the global maximum. It has been show that this procedure creates a Markov chain that converges to the posterior distribution (Lancaster, 2004), which can be used to find the global maximum of the likelihood function.

While the algorithm described above will converge to the desired posterior distribution, the speed of convergence can be slow if the number of parameters is large. To speed up convergence, I make use of a technique called Gibbs sampling. In this algorithm, the parameters are split into sets called blocks, and within one iteration, parameters are drawn from each block sequentially rather than all at once. When Gibbs sampling is combined with the Metropolis-Hastings algorithm, the speed of

\footnotetext{
${ }^{32}$ In a more general form, this probability is a function of objects called the proposal density and the prior, but the probability reduces to this simpler form in equation (5) if the prior is noninformative and the proposal densities are symmetric.

${ }^{33}$ While convergence to the posterior distribution is guaranteed with the use of any proposal density that satisfies these conditions, in practice, the speed of convergence is better if the proposal density is chosen such that the percentage of parameters that are accepted is around $30 \%$ (Ching, Imai, Ishihara, and Jain, 2012).
} 
convergence to the posterior distribution increases (Ching, Imai, Ishihara, and Jain, 2012)..$^{34}$

\subsection{Value Function Approximation}

One of the arguments in the likelihood function shown above is the value function. Because the value function is itself a function of the parameters, it needs to be reevaluated every time a new proposal parameter $\theta^{* k}$ is drawn in the Metropolis-Hastings algorithm. A researcher could obtain the value function for each new parameter by applying the Bellman operator repeatedly until the value function converges, but doing so would be computationally burdensome. This computational problem can be alleviated by using the IJC (2009) algorithm. In this algorithm, when a new parameter is drawn, the value function is instead approximated with a weighted average of previous evaluations of the value function. I construct these previous evaluations by applying the Bellman operator only once for each iteration in the MCMC estimation algorithm. Imai, Jain, and Ching (2009) prove that their algorithm leads to convergence for both the value function and the posterior distribution.

To incorporate the IJC (2009) algorithm into my estimation routine, I replace the expectation of the value function $E V\left(S_{t}, \theta\right)$ in equation (5) with the approximation $\widehat{E V}^{k}\left(S_{t}, \theta\right)$ that is a weighted average of expected value functions $E V^{n}\left(S_{t}, \theta^{* n}\right)$ from previous iterations $n .{ }^{35} \mathrm{I}$ express this weighted average as

$$
\widehat{E V}^{k}\left(S_{t}, \theta\right)=\sum_{n=N(k)}^{k-1} E V^{n}\left(S_{t}, \theta^{* n}\right) \frac{K_{h}\left(\theta-\theta^{* n}\right)}{\left(\sum_{n^{\prime}=N(k)}^{k-1} K_{h}\left(\theta-\theta^{* n^{\prime}}\right)\right)}
$$

\footnotetext{
${ }^{34}$ This happens because the probability a parameter is accepted is inversely related to both the number of parameters that are drawn and the variance of the proposal densities. So if fewer parameters are drawn at once, the variance of the proposal densities can be larger. This allows for bigger steps to be taken, which speeds up convergence.

${ }^{35}$ IJC (2009) construct this weighted average using value functions, not expected value functions. I use the latter object because I am able to efficiently integrate over the distribution of my random variables when I iterate the value function.
} 
in which $N(k)$ is the lower bound for the set of past iterations to use and $K_{h}(\cdot)$ is a multivariate kernel with bandwidth $h$. In this approximation, if a past $\theta^{* n}$ is closer to the current parameter $\theta$ than the other past parameters, then the value function for this $\theta^{* n}$ is given more weight. To construct $E V^{n}\left(S_{t}, \theta^{* n}\right)$, I modify the definition for the value function in equation (4) to express $E V^{n}\left(S_{t}, \theta^{* n}\right)$ as

$$
\begin{array}{r}
E V^{n}\left(S_{t}, \theta^{* n}\right)= \\
E\left[\left(\max _{C_{t+1}, D_{t+1}} U\left(C_{t+1}, D_{t+1}, J_{t+1}^{\prime}, \epsilon_{t+1}, S_{t+1}, \theta^{* n}\right)+\widehat{E V}^{n}\left(S_{t+1}, \theta^{* n}\right)\right) \mid S_{t}, \theta^{* n}\right] .
\end{array}
$$

In appendix A.2, I discuss my value function approximation in more detail.

\subsection{Modifications to IJC (2009) Algorithm}

The model I have developed contains many more state variables than the models presented in Imai, Jain, and Ching (2009) and Ching, Imai, Ishihara, and Jain (2012). This increases the difficulty in solving for my value function by increasing the dimensionality of the integral used to evaluate the expectation of the value function and by increasing the number of points at which the value function needs to be evaluated. Because of these difficulties, I make several modifications to the IJC (2009) algorithm. First, in order to evaluate the expectation of the value function with respect to continuous variables, I make use of multidimensional quadrature rules based on Smolyak's (1963) algorithm. In these quadrature rules, the number of points at which the integrand is evaluated only grows polynomially rather than exponentially with the number of dimensions. This allows me to evaluate the expectation of my value function feasibly, given that I have several continuous variables.

The other modification I make centers around the construction of my interpolation function. The approximation procedure described in section 6.2 requires the evaluation of the value function at every point in the state space. For example, if $S_{t}$ 
can be one of a million different quantities, then an evaluation of the value function needs to be created for each of these million different points. If the state space is continuous, then technically an infinite number of values needs to be stored, which is impossible given finite computer memory. I address this problem by storing evaluations of the value function at a finite number of grid points and then constructing a multidimensional interpolation function based on splines in order to evaluate the value function at other points. Some multidimensional splines suffer from the curse of dimensionality in which the number of required grid points grows exponentially with the number of state variables (Judd, 1998). I avoid this problem by picking my grid points in such a way that they only grow polynomially, rather than exponentially, with the number of state variables. I do this by selecting one central state point and then constructing other points that deviate from this central point in only one or two dimensions. Results from papers on multidimensional interpolation, such as Smolyak (1963), suggest that choosing grid points with this approach allows a researcher to achieve the highest level of accuracy for a given number of grid points. ${ }^{36}$

\subsection{Likelihood Construction}

My likelihood function $\mathscr{L}\left(Y \mid \theta, E V\left(S_{t}, \theta\right)\right)$ represents the probability of observing the wages, hours worked, assets, and employment and non-employment durations and transitions that I see in the data. The construction of this function is complicated by the fact that I do not observe job offers that are rejected, unobserved heterogeneity, and non-pecuniary benefits. I also assume that wages and assets are measured with error, which makes the true value of these variables unknown as well. Integrating over the distribution of all these variables could make my likelihood function difficult to calculate.

In Bayesian statistics, a method called data augmentation simplifies the construc-

\footnotetext{
${ }^{36} \mathrm{I}$ also use this method to construct a policy function for assets to reduce the number of times I need to maximize a household's value function with respect to assets.
} 
tion of the likelihood. This method works by sequentially drawing unobserved variables conditional on the current parameter $\theta^{k}$ and then drawing $\theta^{k+1}$ conditional on the unobserved variables that were just drawn. This sequential form of sampling is just a variant of Gibbs sampling, which creates a Markov chain that converges to the posterior distribution (Lancaster, 2004). This is in contrast with other methods of integrating out unobserved variables, such as simulation, which can lead to inconsistent estimates due to approximation error. The expression for my likelihood function with data augmentation is given in the appendix.

\subsection{Functional Form Assumptions}

While many parts of my model are identified without functional form assumptions, having these assumptions makes my model much easier to estimate. I assume the job offer probabilities $\lambda_{p}(\cdot)$, birth probabilities $\chi(\cdot)$, job loss probabilities $\eta_{p}(\cdot)$, and UI benefit probabilities $\psi_{p}(\cdot)$ can be expressed with a logistic function $\exp (\cdot) /(1+$ $\exp (\cdot))$ in which the arguments for $\exp (\cdot)$ are a linear combination of the explanatory variables. I let one of these explanatory variables be a spouse's gender, which allows $\lambda_{m}(\cdot), \lambda_{f}(\cdot)$, and similar pairs of probabilities to differ only with respect to this indicator. ${ }^{37}$ For offered wages, I assume that

$$
\ln \left(W_{p, t}^{\prime}\right) \sim N\left(\alpha_{w} X_{p, t}+\nu_{w, p}, \sigma_{w}\right)
$$

I also assume that the time-choice specific shocks $\epsilon_{t}\left(D_{t}\right)$ are distributed iid extreme value $(0,1)$, which allows the acceptance probability $\operatorname{Pr}\left(D_{t} \mid \cdot\right)$ to be a logit or multinomial logit probability depending on whether one or two job offers were received, respectively.

Within the utility function, I assume the consumption function can be expressed

\footnotetext{
${ }^{37}$ I make use of a similar indicator in the wage distribution.
} 


$$
\alpha_{c} \frac{C_{t}^{1-\sigma_{c}}-1}{1-\sigma_{c}},
$$

in which $\sigma_{c}$ is the coefficient of relative risk aversion and $\alpha_{u}$ is the weight that the household places on consumption. With regards to the leisure function within the utility function, I assume that it can expressed as

$$
\alpha_{L, 1}\left(1-\widetilde{H}_{f, t}\left(D_{f, t}\right)\right)+\alpha_{L, 2} 1\left(\widetilde{H}_{m, t}\left(D_{m, t}\right)=0, \widetilde{H}_{f, t}\left(D_{f, t}\right)>0\right),
$$

in which hours worked are normalized to be between zero and one, $\alpha_{L, 1}$ is the weight given to the wife's leisure, and $\alpha_{L, 2}$ represents the disutility assigned to the condition of having the wife working but not the husband. ${ }^{38}$ I include the latter parameter because only $3.63 \%$ percent of households have a wife who is the only employed spouse, as reported in table 10 in section 7.2, so incorporating this parameter allows me to match better the observed distribution of employment frequencies. Finally, I assume the error term in the $\mathrm{AR}(1)$ for the state unemployment rate is normally distributed.

\subsection{Measurement Error}

Datasets in economics based on surveys frequently contain measurement error, which can bias estimation results. I make several modifications to my estimation strategy to reduce the effects of measurement error. One type of measurement error I face relates to the timing of employment transitions reported in the SIPP. Respondents frequently do not remember the exact date they started a new job and will

\footnotetext{
${ }^{38} \mathrm{My}$ normalizing assumption is to set the shape parameter for the extreme value distribution equal to 1. I assume the household does not value the husband's leisure because in initial estimates of my model, the weight for the husband's leisure went to 0 because of the high rates of male labor force participation in my data.
} 
often erroneously report employment transitions happening at the start of a reference period. ${ }^{39}$ This phenomenon is called the seam effect. I control for the seam effect by including indicator variables in the job offer and job loss probabilities which account for the higher frequency of employment transitions being reported at the start of a reference period..$^{40}$

Others variables that I allow to be measured with error are wages and assets. I assume the relationship between observe wages $W_{p, t}^{\text {data }}$ and unobserved wages $W_{p, t}$ takes the form

$$
\ln \left(W_{p, t}^{\text {data }}\right) \sim N\left(\ln \left(W_{p, t}\right), \sigma_{w, p}^{\text {data }}\right) .
$$

Because I cannot separately identify the variance of non-pecuniary benefits and wage measurement error, since both variables allow spouses to accept and keep lower-paying jobs, I set the variance for the measurement error of log wages equal to the estimates from Bound and Krueger (1991). These estimates are based on comparisons between linked survey and administrative data. For assets, I let

$$
A_{t}^{\text {data }} \sim N\left(A_{t}, \exp \left(\alpha_{A, 0}+\alpha_{A, 1} A_{t}\right)\right)
$$

in which the error variance for observed assets is heteroskedastic with respect to a household's true unobserved assets. My estimates of this variance captures both error in reported assets as well the degree to which my models fails to explain the level of assets that are observed for each household.

\footnotetext{
${ }^{39}$ For example, if respondents are asked about their employment activity between January $1^{\text {st }}$ and April $30^{\text {th }}$, they may frequently say that they started their new jobs January $1^{\text {st }}$ when in fact they started their jobs sometime in February.

${ }^{40}$ In the job offer probability, this indicator variable equals one if the month in question is the first month in a reference period. For the job loss probability, this variable equals one if the month in question is the last month in the reference period.
} 


\section{Results}

\subsection{Parameter Estimates}

In this section, I present estimates of my structural parameters. Table 7 presents estimates of the parameters that are estimated with my Bayesian MCMC algorithm, and Table 8 presents estimates of the parameters that are estimated outside of my Bayesian MCMC algorithm as well as fixed parameters. ${ }^{41}$ In the estimates in Table 7, the sign of most variables are as expected. For example, households are less likely to receive a job offer in any given month if the unemployment rate is high, and spouses with a college education receive higher wage offers, on average, than spouses without a college education. To put the size of the coefficients of the job offer probability into perspective, consider the example of a husband who has been unemployed for six months in a state with a $9 \%$ unemployment rate. The probability he receives a job offer in a particular month is $20.86 \%$. For this same man, the job offer probability decreases by 1.02 percentage points if the unemployment rate increases by one percentage point and decreases by 3.13 percentage points if he is without work for one additional month. ${ }^{42}$

Because I use log values, the parameters in the wage distribution represent percentage changes in the mean of the wage distribution. For example, my estimate of the "Female" parameter shows that husbands on average receive wage offers that are $21.5 \%$ higher than their wives. One surprising result for this set of parameters is that the unemployment rate is associated with higher wage offers, although the coefficient is not statistically significant. However, a higher unemployment rate is still associated with less desirable outcomes because the coefficient for this variable

\footnotetext{
${ }^{41}$ Some of these parameters can be estimated outside of the main algorithm because they describe transitions, such as births or job losses, which do not depend on the household's value function or the household's unobserved heterogeneity. See Aguirregabiria and Mira (2010) for further discussion.

${ }^{42}$ These calculations ignore the seam effect parameter.
} 
Table 7: Table of Estimates for Structural Parameters Estimated with Bayesian MCMC Algorithm

\begin{tabular}{|c|c|c|c|}
\hline \multicolumn{2}{|c|}{ Job Offer Probability } & \multicolumn{2}{|c|}{ Log Wage Distribution } \\
\hline Constant & $\begin{array}{l}0.444^{* * *} \\
(0.119)\end{array}$ & Constant & $\begin{array}{l}1.61^{* * *} \\
(0.046)\end{array}$ \\
\hline Unemployment Rate & $\begin{array}{l}-0.063^{* * *} \\
(0.007)\end{array}$ & Part-Time & $\begin{array}{l}-0.259^{* * *} \\
(0.024)\end{array}$ \\
\hline Employed & $\begin{array}{l}-6.02^{* * *} \\
(0.152)\end{array}$ & Unemployment Rate & $\begin{array}{l}0.003^{* *} \\
(0.002)\end{array}$ \\
\hline Length Non-Employed & $\begin{array}{l}-0.202^{* * *} \\
(0.009)\end{array}$ & Age in Decades & $\begin{array}{l}0.399^{* * *} \\
(0.020)\end{array}$ \\
\hline Female & $\begin{array}{l}0.466^{* * * *} \\
(0.049)\end{array}$ & $\begin{array}{l}\text { Age in Decades } \\
\text { Squared }\end{array}$ & $\begin{array}{l}-0.004^{* * *} \\
(0.000)\end{array}$ \\
\hline Seam Effect & $\begin{array}{l}2.08^{* * *} \\
(0.079)\end{array}$ & White & $\begin{array}{l}0.108^{* * *} \\
(0.011)\end{array}$ \\
\hline Part-time Probabi & ity & High School & $\begin{array}{l}0.131^{* * *} \\
(0.021)\end{array}$ \\
\hline Probability & $\begin{array}{l}0.250^{* * *} \\
(0.013)\end{array}$ & Some College & $\begin{array}{l}0.284^{* * *} \\
(0.015)\end{array}$ \\
\hline Utility Function & & College & $\begin{array}{l}0.668^{* * *} \\
(0.018)\end{array}$ \\
\hline Wife's Leisure Weight & $\begin{array}{l}0.041^{* * *} \\
(0.011)\end{array}$ & Female & $\begin{array}{l}-0.215^{* * *} \\
(0.008)\end{array}$ \\
\hline Reversed Gender Roles Cost & $\begin{array}{l}-0.161^{* * *} \\
(0.045)\end{array}$ & Standard Deviation & $\begin{array}{l}0.225^{* * *} \\
(0.004)\end{array}$ \\
\hline Consumption Weight & $\begin{array}{l}2.03^{* * *} \\
(0.081)\end{array}$ & Wage Unobserved & Heterogeneity \\
\hline Relative Risk Aversion & $\begin{array}{l}2.49^{* * *} \\
(0.040)\end{array}$ & Husband's Variance & $\begin{array}{l}0.095^{* * *} \\
(0.004)\end{array}$ \\
\hline Asset Measurement & Error & Wife's Variance & $\begin{array}{l}0.114^{* * *} \\
(0.004)\end{array}$ \\
\hline Constant & $\begin{array}{l}9.13^{* * *} \\
(0.051)\end{array}$ & Covariance & $\begin{array}{l}0.054^{* * *} \\
(0.004)\end{array}$ \\
\hline $\begin{array}{l}\text { Abs. Value Unobs. Assets } \\
\text { in } 100 \mathrm{Ks}\end{array}$ & $\begin{array}{l}1.71^{* * *} \\
(0.031)\end{array}$ & & \\
\hline
\end{tabular}

Number of Observations: 9,622

Number of MCMC iterations: 40,000

Number of MCMC iterations used to construct means: 20,000

Table describes estimates of the structural parameters that are estimated with my Bayesian MCMC algorithm using data from the SIPP. See Table 1 for more details on the data. Posterior means are displayed first followed by posterior standard deviations. The seam effect indicator is described in section 6.6. The significance asterisks for the Frequentist (non-Bayesian) p-values are: ${ }^{* * *} \mathrm{p}<0.01,{ }^{* *} \mathrm{p}<0.05,{ }^{*} \mathrm{p}<0.1$. 
Table 8: Table of Estimates for Structural Parameters Estimated Outside the Main Bayesian MCMC Algorithm

\begin{tabular}{|c|c|c|c|}
\hline \multicolumn{2}{|c|}{ Job Loss Probability } & \multicolumn{2}{|c|}{ UI Probability } \\
\hline Constant & $\begin{array}{l}-3.22^{* * *} \\
(.039)\end{array}$ & Constant & $\begin{array}{l}-0.793^{* * *} \\
(0.043)\end{array}$ \\
\hline Unemployment Rate & $\begin{array}{l}0.010^{* *} \\
(.005)\end{array}$ & Female & $\begin{array}{l}-0.892^{* * *} \\
(0.070)\end{array}$ \\
\hline Length Employed & $\begin{array}{l}-0.039^{* * *} \\
(.001)\end{array}$ & Birth Pro & bability \\
\hline Female & $\begin{array}{l}0.162^{* * *} \\
(.022)\end{array}$ & Constant & $\begin{array}{l}-4.90 * * * \\
(0.032)\end{array}$ \\
\hline Seam Effect & $\begin{array}{l}0.472^{* * *} \\
(.023)\end{array}$ & $\begin{array}{l}\text { Number of Kids } \\
\text { Age Youngest }\end{array}$ & $\begin{array}{l}-0.002 \\
(0.021) \\
-0.103^{* * *} \\
(0.006)\end{array}$ \\
\hline Log Wage Measuremer & t Error S.D. & State Unemp. & Rate $\operatorname{AR}(1)$ \\
\hline Male & 0.338 & Constant & $0.012^{* * *}$ \\
\hline $\begin{array}{l}\text { Female } \\
\qquad \text { Other Fixed Para }\end{array}$ & meters & Correlation & $\begin{array}{l}(0.002) \\
0.999 * * * \\
(0.0004)\end{array}$ \\
\hline $\begin{array}{l}\text { Discount Factor } \\
\text { Asset Lower Bound } \\
\text { Interest Rate } \\
\text { Min. Consumption Value }\end{array}$ & $\begin{array}{l}0.99 \\
0 \\
0.01 \\
1.0 \mathrm{E}-7\end{array}$ & Error S.D. & 0.0184 \\
\hline
\end{tabular}

Table describes parameters which are estimated outside of my Bayesian MCMC algorithm as well as fixed parameters. The parameters in the job loss, UI, and birth probabilities are estimated with the SIPP using MLE, and the unemployment rate parameters are estimated with state unemployment rate data from the BLS using OLS. The measurement error parameters for log wage are taken from Bound and Krueger (1991). The significance asterisks for the $\mathrm{p}$-values are: ${ }^{* * *} \mathrm{p}<0.01,{ }^{* *} \mathrm{p}<0.05,{ }^{*} \mathrm{p}<0.1$ 
in the job offer probability is negative and large in magnitude. For the unobserved heterogeneity in the wage distribution, the correlation between the husband's and the wife's unobserved heterogeneity is 0.52 , which suggests that husbands and wives often have similar unobserved labor market abilities.

In the utility function, the "Wife's Leisure Weight" and "Utility Weight" parameters, which are $\alpha_{L, 1}$ and $\alpha_{C}$ in equations 9-10, respectively, gives some indication of how well my model fits the data. For example, if the value of these parameter were 0, it would imply that my value function does not help explain choice probabilities and that households in essence flip a coin to decide whether to accept a job offer. Both of these parameters are statistically significant with a Frequentist (non-Bayesian) interpretation of the posterior means and standard deviations, suggesting that my value function help my model better predict employment transitions. Another key parameter in the utility function is the coefficient of relative risk aversion, which has a posterior mean of 2.49 . This mean is within the range of $[1,5]$ that many economists believe contains this parameter (Chetty, 2003), implying that my estimates of this parameter are reasonable. The "Reversed Gender Roles Cost", which affects households in which the wife is the only employed spouse, is negative because of the low observed frequency of such households in my dataset.

Finally, the parameters in the asset measurement error equation show that there are sizable discrepancies between observed assets and my model's theoretical predictions. As shown in equation (12), the standard deviation for observed assets $A_{t}^{\text {data }}$ takes the form $\exp \left(\alpha_{A, 0}+\alpha_{A, 1} A_{t}\right)$, which is heteroskedastic with respect to unobserved assets $A_{t}$. To put the magnitude of these parameters into perspective, when a household's true, unobserved assets are $\$ 30,000$, the standard deviation is $\$ 15,356$. The size of this standard deviation is large, but not unreasonable given how noisy asset measures typically are in survey data. In the future, I may be able to reduce 
the magnitude of these estimates by introducing heterogeneity into the coefficient of relative risk aversion or the discount factor. Currently, my model cannot explain why some households would not accumulate assets while a husband or wife was working in order to adequately insure against a job loss. However, if I allow some households either to discount the future heavily or to lack aversion to low consumption, then my model may be better able to match the observed distribution of assets.

\subsection{Goodness-of-Fit}

Table 9: Goodness-of-Fit Analysis on Employment Transitions

\begin{tabular}{lllll}
\multicolumn{5}{c}{ Predicted Probabilities } \\
\hline Prob. Sextile & Both Reject & Husband Accepts & Wife Accepts & Both Accept \\
1st & 0.8696 & 0.0011 & 0.0019 & $<10^{-5}$ \\
2nd & 0.9727 & 0.0013 & 0.0024 & $<10^{-5}$ \\
3rd & 0.9950 & 0.0014 & 0.0028 & $<10^{-5}$ \\
4th & 0.9957 & 0.0015 & 0.0031 & $<10^{-5}$ \\
5th & 0.9962 & 0.0065 & 0.0135 & 0.0001 \\
6th & 0.9969 & 0.0821 & 0.0542 & 0.0021 \\
& \multicolumn{5}{|}{} \\
& \multicolumn{5}{c}{ Observed Frequencies } & \\
\hline Prob. Sextile & Both Reject & Husband Accepts & Wife Accepts & Both Accept \\
1st & 0.8584 & 0.0003 & 0.0011 & 0 \\
2nd & 0.9634 & 0.0003 & 0.0010 & 0 \\
3rd & 0.9949 & 0.0005 & 0.0008 & 0 \\
4th & 0.9987 & 0.0002 & 0.0015 & $<10^{-4}$ \\
5th & 0.9985 & 0.0117 & 0.0193 & 0.0019 \\
6th & 0.9987 & 0.0786 & 0.0651 & 0.0050
\end{tabular}

Statistical Test: $\chi^{2}(23)=0.0441, \mathrm{p}=1.0000$

Table describes results from a goodness-of-fit analysis on employment transition probabilities. In this table, households are stratified based on their predicted probabilities for each type of employment transition. The group of households in each sextile is specific to each outcome (e.g. households in the $1^{\text {st }}$ sextile for "Both Reject" are most likely present in higher sextiles for the outcome "Husband accepts). The top half of the table reports average predicted probabilities for each sextile and the bottom half reports the observed frequency for the same sextile (e.g. the $2^{\text {nd }}$ sextile for "Husband Accepts" in the top and bottom tables contains the same set of households). The unit of time in this table is one month. The last line reports a Pearson's chi-square test statistic comparing the predicted probabilities to the observed frequencies. A p-value less that .05 would indicate that the distribution of observed frequencies is statically significantly different from the distribution of predicted probabilities. 
In this subsection, I present results summarizing the goodness-of-fit of my model. Table 9 describes how well my model explains monthly employment transitions probabilities. In my model, four potential employment-related events can occur in any given month: (1) Both spouses either reject a job offer or do not receive one, (2) only the husband starts a new job, (3) only the wife starts a new job, or (4) both start a new job. For every household in my sample, I calculate the probability of these four events occurring for any given month. ${ }^{43}$ To test how well these predicted probabilities match observed frequencies, I stratify households by the percentile of their predicted probabilities and then compare the average predicted probabilities to the observed frequencies for each stratum. This approach allows me to assess whether households that are predicted by my model to be more likely to experience employment transitions actually experience those transitions with greater frequency in the data. The results in this table suggest that my model performs well in explaining employment transitions. For example, in the $5^{\text {th }}$ sextile for the outcome of both spouses not starting a new job, the average predicted probability is $99.62 \%$ and the observed frequency is $99.85 \%$. A chi-square test also shows that there is no statistically significant difference between the observed and predicted frequencies reported in Table 9. This analysis is robust to the number of strata used to group households.

In addition to analyzing employment transitions, I also evaluate how well the stationary distributions of wages, assets and employment in my model matches the observed cross-sectional distributions in Table 10 and Figure 3. Overall, my model does well at explaining the cross-sectional distribution of employment outcomes, but worse at explaining the observed distribution of wages and assets. In the wage and assets distributions, my model underpredicts the percentiles in these distributions. For example, the predicted median of hourly wages for husbands with a job is $\$ 17.15$,

\footnotetext{
${ }^{43}$ These probabilities are multidimensional integrals of multinomial logit probabilities, so I use simulation to calculate these probabilities.
} 
Table 10: Comparison of Observed Cross-Sectional Distribution to Model's Stationary Distribution

\begin{tabular}{l|ll|ll|ll} 
& \multicolumn{2}{|c|}{ Husband's Wage } & \multicolumn{2}{|c|}{ Wife's Wage } & \multicolumn{2}{c}{ Household Assets } \\
Percentile & Obs. & Predict. & Obs. & Predict. & Obs. & Predict. \\
$10^{\text {th }}$ & $\$ 10.05$ & $\$ 9.41$ & $\$ 8.82$ & $\$ 8.09$ & $\$ 57$ & $\$ 1$ \\
$25^{\text {th }}$ & $\$ 14.75$ & $\$ 12.06$ & $\$ 11.67$ & $\$ 11.08$ & $\$ 5,494$ & $\$ 1$ \\
$50^{\text {th }}$ & $\$ 21.26$ & $\$ 17.15$ & $\$ 16.60$ & $\$ 13.90$ & $\$ 48,372$ & $\$ 8,389$ \\
$75^{\text {th }}$ & $\$ 30.18$ & $\$ 23.16$ & $\$ 24.61$ & $\$ 17.75$ & $\$ 181,594$ & $\$ 29,862$ \\
$90^{\text {th }}$ & $\$ 42.22$ & $\$ 29.38$ & $\$ 33.57$ & $\$ 21.28$ & $\$ 250,000$ & $\$ 149,998$ \\
& & & & & & \\
\hline
\end{tabular}

\begin{tabular}{l|cc} 
& \multicolumn{2}{|c}{ Husband's Wage (2004 Panel) } \\
Percentile & Obs. Starting Wage & Obs. New Wage. \\
$10^{\text {th }}$ & $\$ 11.35$ & $\$ 8.59$ \\
$25^{\text {th }}$ & $\$ 15.24$ & $\$ 11.14$ \\
$50^{\text {th }}$ & $\$ 21.62$ & $\$ 16.07$ \\
$75^{\text {th }}$ & $\$ 31.37$ & $\$ 24.00$ \\
$90^{\text {th }}$ & $\$ 45.00$ & $\$ 33.16$ \\
& & \\
\hline
\end{tabular}

Employment Outcomes

\begin{tabular}{l|ll} 
Outcome & Obs. & Predict. \\
Both Not Working & 0.0142 & 0.0017 \\
Husband Working & 0.2431 & 0.2963 \\
Wife Working & 0.0363 & 0.0127 \\
Both Working & 0.7063 & 0.6893 \\
& & \\
\hline
\end{tabular}

Tables describe how well the stationary distribution of my model matches the observed cross-sectional distribution. The top table shows the percentiles of the observed and simulated distributions for the husband's wage, the wife's wage and household assets. The wages distribution is conditional on a spouse being employed. The middle table looks at the wages of husbands in the 2004 Panel and compares their distribution of wages at the start of the panel to the distribution of wages that are accepted during the course of the panel. The bottom table compares the observed and simulated distribution of employment outcomes. 
Figure 3: Comparison of Observed Cross-Sectional Distribution to Model's Stationary Distribution

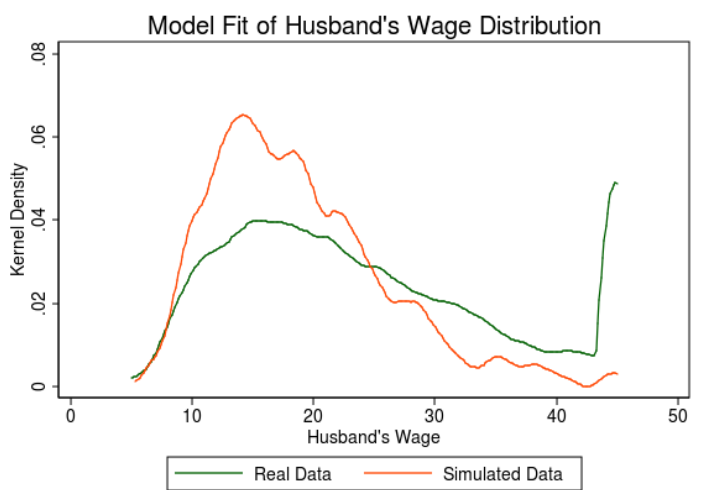

(a)

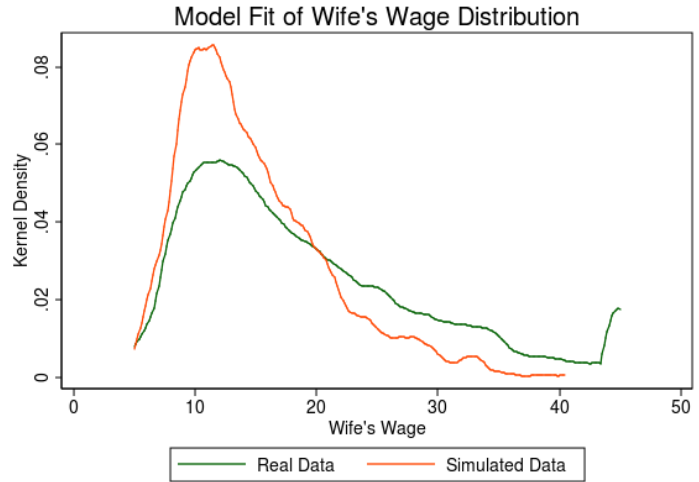

(b)

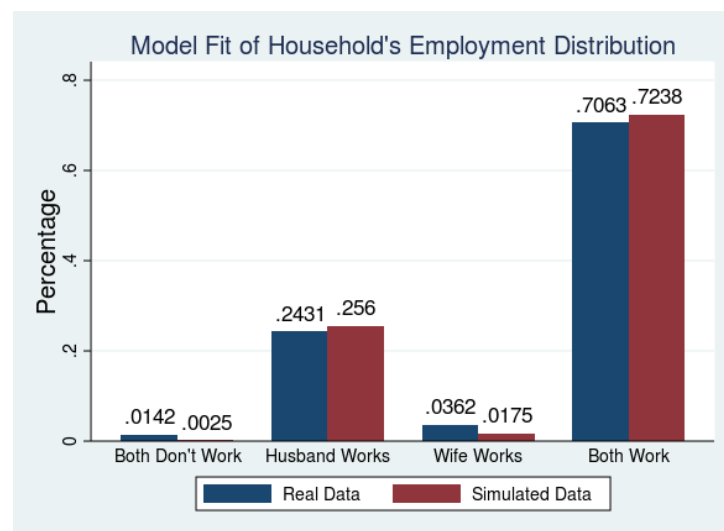

(c)

Graphs visually depict the information presented in Table 10. See this table for more details.

but the observed median is $\$ 21.26$. I discuss earlier in this section why my model may have problems in matching the observed distribution of assets. As for wages, the reason my model may be underpredicting this variable is because I currently ignore the initial conditions problem and because the wages spouses have at the start of the panel are on average higher that the wages that are accepted during the course of the panel. The middle table in Table 10 shows this discrepancy in wages for husbands in the 2004 Panel. I use the 2004 Panel because the national unemployment rate is relatively constant during the course of this panel. The median wages for jobs held 
at the start of the panel is $\$ 21.62$, but the median for jobs accepted during the panel are only $\$ 16.07$. The median of accepted wages may be lower because the spouses who accept new jobs are primarily those who either lose a job during the panel or started the panel with a low-paying job, while spouses who start the panel with a high wage are more likely to reject other job offers that come along. Because I do not account for the initial conditions problem, only wages from job offers that are accepted enter the likelihood function, which could create the bias that I observe. ${ }^{44}$ Accounting for the initial conditions problem in the future may allow me to correct for this bias. In summary, my model does well at explaining employment transitions and cross-sectional frequencies, but less well at explaining wages and assets. In the future, addressing the initial conditions problem and incorporating unobserved heterogeneity into the discount factor or the coefficient of relative risk aversion may allow me to match better the distribution for these variables.

\subsection{Policy Simulations on UI Maximum Benefits}

In this subsection, I use the estimates from my model to address the following research questions: (1) How do changes in UI maximum benefits affect household labor supply? and (2) How is household responsiveness to changes in UI maximums affected by liquid assets or spousal income? To explore these questions, I conduct a series of policy simulations in which the outcome of interest is the employment distribution for 40,000 hypothetical households six months after a job loss. I create these hypothetical households by randomly selecting married couples from the entire SIPP dataset and then modifying key variables. Because I randomly select households from the SIPP, the results from my policy simulations are analogous to the average

\footnotetext{
${ }^{44}$ To be more precise, the wage a spouse has at the start of the panel can affect their subsequent employment transition probabilities, so such wages still affect the likelihood to some degree. Even still, because I ignore the initial conditions problem, more weight is given to wages from job offers that are accepted during the course of the panel when my program estimates the wage distribution.
} 
marginal effect from the estimates of a probit model. ${ }^{45}$ Once a hypothetical household is created, I simulate outcomes for the household (such as whether the wife receives a job offer) for each of the six months based on my parameter estimates, and the household decides whether to accept a job offer based on the simulated outcomes. The key variables which vary in these simulations are the UI maximum, initial household assets, and whether the other spouse was working or not at the time of the job loss.

The changes in the UI maximum benefit which occur in these simulations have two effects on household behavior. The primary effect is that an increase in the UI maximum increases the amount of UI benefits many spouses receives after a job loss, which increases the value of being jobless. However, there is also a secondary effect in which job offers with high wages provide an even greater value to the household when the UI maximum is increased. This occurs because these high-wage job offers would lead to even greater UI benefits in the future if the spouse ever lost the proposed job. My structural model allows me to account for both of these effects. While the primary effect should dominate the secondary effect, both effects still need to be accounted for to properly analyze the impact of changes in the UI maximum on household search behavior.

To describe the results of my policy simulations, I first present graphs on selected outcomes in Figure 4. Within Figure 4, Graph 4a describes employment outcomes from policy simulations in which only the husband was working before he lost his job and Graph 4b describes analogous results for the wife. These graphs also depict separate probabilities for (1) households with no assets and (2) households with assets. The most important result depicted by Figure 4 is that households without assets are more sensitive to changes in the UI maximum, although the overall effect sizes are small to moderate. For example, the probability that the husband is employed six

\footnotetext{
${ }^{45}$ Also note that my average effects are for the entire population and not just for the types of households who experience a job loss.
} 
Table 11: Triple Difference Estimator for Probability Husband is Working Six Months After His Job Loss

\begin{tabular}{llll} 
& UI Max $=\$ 200$ & UI Max $=\$ 400$ & Difference \\
\hline Group A: Wife Not Working & & & \\
Households With Assets & 0.7841 & 0.7754 & -0.0087 \\
Households Without Assets & 0.8857 & 0.8114 & -0.0743 \\
Difference-in-Difference & & & $\mathbf{- 0 . 0 6 5 6}$ \\
& UI Max $=\$ 200$ & UI Max $=\$ 400$ & Difference \\
& & & \\
\hline Group B: Wife Working & 0.9004 & 0.8976 & -0.0028 \\
Households With Assets & 0.9002 & -0.0055 \\
Households Without Assets & 0.9057 & & $\mathbf{- 0 . 0 0 2 7}$ \\
Difference-in-Difference & & & $\mathbf{0 . 0 6 2 9}$ \\
& & &
\end{tabular}

See notes from Figure 4. The range for the UI maxima used in this table reflects the actual range for this variable across many of the U.S. states. Differences are in terms of probabilities.

Table 12: Triple Difference Estimator for Probability Wife is Working Six Months After Her Job Loss

UI Max $=\$ 200 \quad$ UI Max $=\$ 400 \quad$ Difference

Group A: Husband Not Working

$\begin{array}{llll}\text { Households With Assets } & 0.4043 & 0.3824 & -0.0219\end{array}$

Households Without Assets $\quad 0.5327 \quad 0.4445 \quad-0.0882$

Difference-in-Difference $\quad \mathbf{- 0 . 0 6 6 3}$

UI Max $=\$ 200 \quad$ UI Max $=\$ 400 \quad$ Difference

Group B: Husband Working

Households With Assets

$\begin{array}{lll}0.6001 & 0.5558 & -0.0443\end{array}$

Households Without Assets

$0.6190 \quad 0.5654$

$-0.0536$

Difference-in-Difference

$-0.0093$

Triple Difference

0.0570

See notes from Figure 4 and Table 11. 
Figure 4: Graphs for Policy Experiments on UI Maximum Benefits Household Employment Outcomes Six Months After a Job Loss

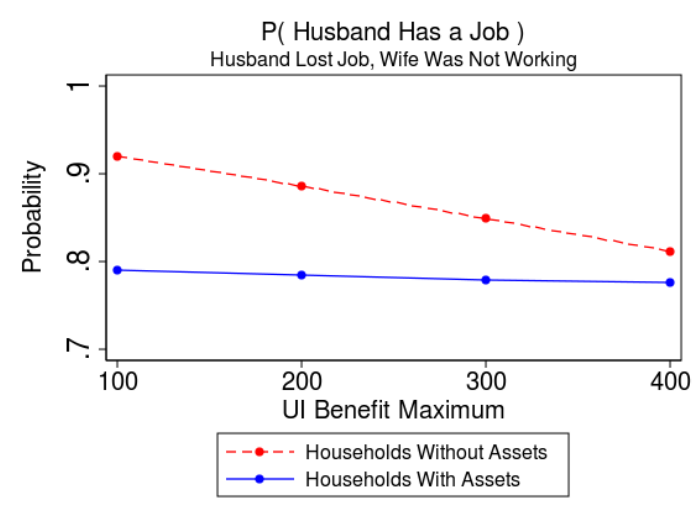

(a)

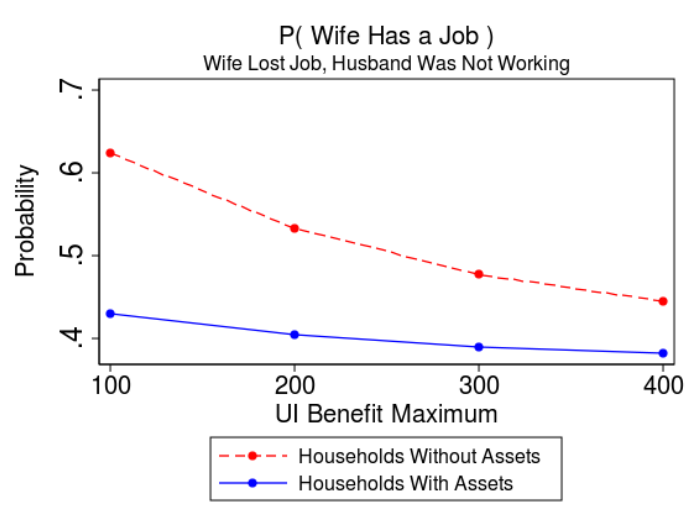

(b)

These graphs describe the results from my policy simulation in which I vary the UI maximum benefit. The outcome of interest is the employment distribution for 40,000 hypothetical households six months after a job loss. I create these hypothetical households by randomly selecting households from the SIPP data and then modifying key variables. In this simulation, all spouses who lose a job receive UI benefits.

months after his job loss decreases in Graph 4a for both sets of households when the UI maximum goes from $\$ 200$ to $\$ 400$. This probability decreases by 7.43 percentage points for households without assets but decreases by only .87 percentage points for households with assets. For other ranges of the UI maximum or when looking at the wife's employment probabilities instead, households without assets are still more responsive to changes in UI benefits than households with assets. However, in these simulations, there is one notable exception which occurs for husbands when the UI Maximum changes from $\$ 500$ to $\$ 600$. In this range, there is a sudden drop in employment probabilities for households with assets, and the decrease in employment probabilities for husbands without assets becomes much closer to the decrease for households with assets. I do not see a similar effect for wives, suggesting that this peculiar result might be due to computational approximation error..

I also explore whether households with no assets become less responsive to changes in the UI maximum if the other spouse was working at the time of the job loss. 
Tables 11 and 12 present triple differences describing the effects of three variables on household employment following a spouse's job loss: UI maximum of $\$ 200$ or $\$ 400$ benefits, liquid assets that are zero or positive, and the employment of a secondary earner. ${ }^{46}$ In Table 11, it may seem odd that husbands are more likely to be employed if their wives are working, but what drives this results is the parameter in my utility function which imposes a cost to having the wife being the only employed spouses, which is included to help me better match the observed distribution of household employment.

The sign and magnitude of the interaction between UI, assets, and spousal employment is given by the triple difference estimates in these tables. The triple difference for the probability that the husband is working six months after his job loss is 0.0629 , and the triple difference for the probability that the wife is working six months after her job loss is 0.057 . The positive value for these two triple difference estimates show that households with no assets become less desperate for an additional source of income if the other spouse is employed at the time of the job loss and are thus less responsive to UI changes. While the absolute differences in the employment probabilities between the groups of households are small to modest, the relative differences are more pronounced. For example, households with no assets become about $88 \%$ less responsive to changes in the UI maximum if they have assets at the time of the husband's job loss. ${ }^{47}$ Overall, my policy simulations show that households which had both no assets and only one spouse working prior to the job loss are moderately re-

\footnotetext{
${ }^{46}$ The construction of the triple differences presented in tables 11 and 12 is different from the construction of triple differences presented in other papers, such as Gruber (1994), because I use simulated data. However, the numbers present in these tables are still estimates because my simulations are based on estimates of the parameters for my model. Also, the typical identification concerns for double and triple difference estimates do not apply for this simulation exercise because I have control over other confounding factors.

${ }^{47}$ This is the relative difference between the differences reported in the last column for Table 11 between households without assets and with the wife not working (-0.0743) and households without assets and the wife working ( -.0087).
} 
sponsive to changes in the UI maximum. These households become less responsive when they either have assets or the other spouse working at the time of the job loss. Because I am able to account for unobserved variables that are correlated with assets and employment, the estimates from these policy simulations can be seen as causal rather than only correlational.

\subsection{Moral Hazard vs. Liquidity Constraints in UI Benefits}

Incorporating this comparison of households with and without assets into my policy simulations allows me to connect my model to the discussion in economics started by Chetty (2008) on moral hazard versus liquidity constraints in UI benefits. This debate focuses on whether the effect of UI in raising unemployment durations is primarily due to a more negative channel of distorting the incentive to work, which Chetty (2008) refers to the "moral hazard" effect, or whether the effect of UI on unemployment durations is primarily due to a more positive channel of giving people without financial resources the ability to smooth consumption across an unemployment spell, which Chetty (2008) labels the "liquidity constraint" effect. The moral hazard and liquidity constraint effects can also be interpreted as substitution and income effects, receptively, since the former refers to how an increase in UI may decrease the relative benefit of receiving a labor income, while the latter refers to how UI may give a household more financial resources during an unemployment spell.

In determining which effect dominants, Chetty's (2008) insight is to compare how households with UI as their sole financial resource during an unemployment spell respond differently to changes in UI from households with an additional financial resources, such as liquid assets. For households with assets, receiving UI would not increase their overall pool of financial resources during an unemployment spell by very much, so such household should only experience a moral hazard effect when faced with an increase in UI benefits. However, for households without assets or a 
secondary earner at the time of the job loss, receiving UI would greatly increase their pool of financial resources during an unemployment spell, so such households should face both a moral hazard and a liquidity-constraint effect.

Therefore, in my policy simulation, I can investigate which effect dominants by comparing households with assets to households without assets, both of which do not have a working spouse at the time of the job loss. When looking at the job search behavior of married men who have lost their jobs, the results from Table 11 suggest that $88 \%$ of the effect of UI on job search behavior is due to the liquidityconstraint effect, while only $12 \%$ is due to the moral hazard effect. ${ }^{48}$ Performing a similar analysis on wives using the results from Table 12 suggests that $75 \%$ of the effect of UI on job search behavior is due to the liquidity-constraint effect, which is lower than the $88 \%$ figure for husbands. This difference may be due to wives having a more elastic labor supply, causing them to be more responsive to changes in UI benefits even at higher levels of assets. These results are somewhat similar to Chetty (2008) who finds that $60 \%$ of the effect of UI on unemployment durations for the general population is due to the liquidity-constraint effect, although my estimates of the proportion due to the liquidity-constraint effect are higher. Overall, my results provide evidence that UI mainly helps households smooth consumption rather than distorting the incentive to work.

\subsection{Policy Experiments on the Maximum Duration of Bene- fits}

To conclude this section, I present some brief analyses on the maximum duration of benefits and compare these results to the previous analysis on the UI maximum benefit.. Before I present the results of these policy simulations, I first present in Table

\footnotetext{
${ }^{48}$ The $12 \%$ percent number is generate by dividing the change in employment probabilities for household with assets and the wife not working, -0.0087, to households without assets and the wife not working, -0.0743 .
} 
Table 13: Descriptive Statistics on the UI Maximum Benefit and Duration

Percent that are or would be bounded by the UI Maximum (SIPP)

Unemployed Spouses 25.51\%

Employed Spouses $\quad 49.48 \%$

\begin{tabular}{lll} 
Distribution of remaining UI (CPS) & June 2007 & June 2011 \\
\hline No UI Left & $16.61 \%$ & $15.16 \%$ \\
0-6 Weeks Left & $10.24 \%$ & $0.51 \%$ \\
>6 Weeks Left & $73.15 \%$ & $84.34 \%$
\end{tabular}

Descriptive Statistics on the maximum amount of UI Benefits and the maximum duration of UI Benefits. In the first table, the percent of the unemployed that are bounded by the maximum are the percentage of unemployed spouses who are receiving UI in which the value of the UI maximum benefit for the state they live in minus their UI benefits is less than $\$ 40$. The percentage of employed spouses that would be bounded by the maximum is the percentage of spouses in which their current weekly wage times the replacement rate for the state they live in is greater than the UI maximum for the state they live in. Both figures are calculated with the SIPP. The second table is calculated with the June 2007 and June 2011 CPS. The distribution in this table is the distribution of the maximum UI duration for the state the unemployed worker lives in minus their unemployment duration.

Table 14: Policy Experiment of Maximum UI Duration

\begin{tabular}{llll} 
& UI Duration $=$ & UI Duration $=$ & \\
& 7 Months & 8 Months & Difference \\
\hline Wife Not Working & & & \\
Households With Assets & 0.7679 & 0.7676 & -0.0003 \\
Households Without Assets & 0.8061 & 0.8058 & -0.0003 \\
Difference-in-Difference & & & $\mathbf{0 . 0 0 0 0}$
\end{tabular}

See notes from Figure 4. These policy experiments resemble the ones for figure 4 except the UI duration is varied instead. I obtain similar results for when the wife is the job loser and when the other spouse is working at the time of the job loss. 
13 some descriptive statistics about how the maximum amount of benefits and the maximum duration of befits affect married households. For the maximum amount of benefits, Krueger and Meyer (2002) find that around 35\% of the unemployed receive the maximum benefit. However, this statistic is for the general population, so the number may change for married couples. To look at how the maximum affects married couples during and prior to an unemployment spell, I examine both the UI benefits currently unemployed spouses receive as well as the amount of benefits a spouse may receive if they became unemployed. Because UI Benefits are measured with error, I classify an unemployed spouse as being bounded by the maximum if the value of the maximum amount of UI benefits in the household's state minus the spouse's current UI benefits is less than $\$ 40$. With this criteria, I get that $25.51 \%$ of unemployed spouses are receiving the maximum duration of benefits. On the other hand, if I look at whether the UI benefits an employed spouses would receive if they lost his or her job is bounded by the maximum, I get that $49.48 \%$ would receive the maximum amount of benefits, so many of these households would be affected by the maximum if they became unemployed. ${ }^{49}$ This discrepancy is likely due to unemployed spouses having lower wages on average than other spouses who experience spells of unemployment with a lower likelihood.

In table 13, I also look at how spouses are affected by the maximum duration of benefits. Because the SIPP is a short panel which does not ask directly how long a spouse has been unemployed, I look at the CPS to evaluate how often unemployed spouses are affected by the maximum duration of benefits. ${ }^{50}$ Because the maximum

\footnotetext{
${ }^{49}$ To get a spouse's potential UI Benefits, I use my approximation of UI benefits rules in which spouses receive a fraction of their previous wage, up unto a maximum benefit amount. While actual UI benefits rules are more complicated, this formula is a good approximation which captures the important features of the UI system.

${ }^{50}$ If a spouse starts the SIPP Panel without a job, the survey asks the year the spouse last had a job. I discuss in appendix A.1 how I use this information to construct the duration of unemployment in months.
} 
duration of benefits varies substantially during my time frame of interest, I look at unemployment durations for married individuals in the June 2007 CPS, when the maximum duration was 26 weeks in most states, and June 2011, when the maximum duration was as high as 99 weeks in some states. In Table 13, I look at the percentage of unemployed spouses who have exceed the maximum duration, the percentage who only have 6 weeks or less left of UI benefits, and the percentage who have more than 6 weeks left. ${ }^{51}$ I get that in the June 2007 CPS, $10.24 \%$ of spouses have 6 weeks or less of UI benefits left. In the June 2011 CPS, when the maximum duration is much higher, only $0.51 \%$ have 6 weeks or less left of UI benefits. Overall, these descriptive statistics suggest that the maximum amount of benefits has a stronger influence on household behavior than the maximum duration. At least during the UI duration expansions in the Great Recessions, it seems that married couples are rarely constrained by the maximum duration of benefits.

Results from my policy simulations on maximum UI durations in Table 14 also suggest that the maximum amount of UI benefits has a smaller impact on household behavior. These simulations resemble the ones for the maximum benefit amount, but instead I vary the maximum duration form seven months to eight months. I still look at household employment probabilities six months after a job loss to remove any mechanical issues of the maximum duration causing some household to lose their UI benefits. For husbands with the wife not working, I get that increasing the maximum duration by one month decreases the probability of employment by only 0.03 percentage points. There is no difference between household with and without assets, which may be due to the very small effect size and the absence of an interaction term between the amount of UI left and assets in the interpolation function for my value

\footnotetext{
${ }^{51}$ These statistics are for illustrative purposes only since they rely on the strong assumption that if a spouse does receive UI benefits, they receive it at the start of their unemployment spell, and that the distribution of unemployment durations for spouses who receive benefits is the same as spouses who do not receive UI benefits.
} 
function. ${ }^{52}$ In summary, the results of my policy simulations and descriptive statistics on household UI and unemployment duration suggests that changes in maximum UI benefits amounts have a stronger impact on the labor supply of married couples than changes in the maximum duration of benefits.

\section{Conclusion}

In this paper, I develop a job search model in which married couples jointly decide whether to accept or reject new job offers based on their current assets, wages, and unemployment insurance (UI) benefits. I am able to account for the endogeneity in these key variables through both my identification strategy and incorporation of various forms of unobserved heterogeneity in my model. Accounting for potential endogeneity problems in these variables is one way in which my paper contributes to the work on the added worker effect, UI and liquidity constraints, and household search models. I also make methodological contributions by extending the Bayesian MCMC algorithm developed by Imai, Jain, and Ching (2009) to handle the sizable number of state variables in my model.

My policy simulations show that both assets and spousal employment affect a household's responsiveness to changes in UI benefits, especially among low-wealth households, and that an estimated $75 \%-88 \%$ of the effect of UI on job search behavior is due to the liquidity-constraint effect, while only $12 \%-25 \%$ of the effect is due to the moral hazard effect. Overall, my model allows me to examine how several important financial resources, such as assets, UI benefits, and supplemental labor income, affect a married couple's job search behavior when one spouse loses his or her job. By incorporating these three financial resources, my model achieves a good balance between being feasible to estimate and also able to provide useful insights about household labor supply.

\footnotetext{
${ }^{52} \mathrm{I}$ discuss this in more detail in appendix A.2.
} 


\section{References}

Aguirregabiria, V., And P. Mira (2010): "Dynamic Discrete Choice Structural Models: A Survey," Journal of Econometrics, 156(1), 38-67.

Bound, J., And A. B. Krueger (1991): "The Extent of Measurement Error in Longitudinal Earnings Data: Do Two Wrongs Make a Right?," Journal of Labor Economics, 9, 1-24.

Brown, D. W. (2010): "Essays in Unemployment Insurance," Ph.D. thesis, Massachusetts Institute of Technology.

Burdett, K., And D. Mortensen (1977): "Discussion Labor Supply Under Uncertainty," in Discussion Papers, no. 297. Northwestern University, Center for Mathematical Studies in Economics and Management Science.

Chetty, R. (2003): "A New Method of Estimating Risk Aversion," National Bureau of Economic Research.

(2008): "Moral Hazard vs. Liquidity and Optimal Unemployment Insurance," Journal of Political Economy, 116(2), pp. 173-234.

Chiappori, P.-A. (1992): "Collective Labor Supply and Welfare," Journal of Political Economy, 100(3), pp. 437-467.

Ching, A. T., S. Imai, M. Ishihara, and N. Jain (2012): "A Practitioner's Guide to Bayesian Estimation of Discrete Choice Dynamic Programming Models," Quantitative Marketing and Economics, 10, 1-46.

Cullen, J. B., and J. Gruber (2000): "Does Unemployment Insurance Crowd out Spousal Labor Supply?," Journal of Labor Economics, 18(3), pp. 546-572. 
Dey, M., And C. Flinn (2008): "Household Search and Health Insurance Coverage," Journal of Econometrics, 145(1-2), 43-63.

Donni, O. (2003): "Collective Household Labor Supply: Nonparticipation and Income Taxation," Journal of Public Economics, 87(5), 1179-1198.

Elbers, C., And G. Ridder (1982): "True and Spurious Duration Dependence: The Identifiability of the Proportional Hazard Model," The Review of Economic Studies, 49(3), 403-409.

Flabbi, L., And J. Mabli (2012): "Household Search or Individual Search: Does it Matter? Evidence from Lifetime Inequality Estimates," IZA Discussion Paper.

Flinn, C., And J. Heckman (1982): "New Methods for Analyzing Structural Models of Labor Force Dynamics," Journal of Econometrics, 18(1), 115-168.

Garcia-Perez, J. I., and S. Rendon (2012): "Family Job Search and Consumption," in Structural Estimation of Behavioral Models: A Conference in Honor of Kenneth I. Wolpin.

Gemici, A. (2011): "Family Migration and Labor Market Outcomes," New York University.

GeWeke, J. (2005): Contemporary Bayesian Econometrics and Statistics, vol. 537. Wiley-Interscience.

Gruber, J. (1994): "The Incidence of Mandated Maternity Benefits," The American Economic Review, 84(3), 622-641.

Guler, B., F. Guvenen, And G. L. Violante (2009): "Joint-Search Theory: New Opportunities and New Frictions," National Bureau of Economic Research Working Paper Series, No. 15011. 
Heckman, J. (1981): "The Incidental Parameters Problem and the Problem of Initial Conditions in Estimating a Discrete Time-Discrete Data Stochastic Process," in Structural Analysis of Discrete Data with Econometric Applications, ed. by C. F. Manski, and D. McFadden, pp. 179-195. MIT Press Cambridge, MA.

Heckman, J. J., And T. MaCurdy (1982): "Corrigendum on a Life Cycle Model of Female Labour Supply," Review of Economic Studies, 49(4), 659-660.

Honoré, B. E. (1993): "Identification Results for Duration Models with Multiple Spells," The Review of Economic Studies, 60(1), 241-246.

Imai, S., N. JAin, And A. Ching (2009): "Bayesian Estimation of Dynamic Discrete Choice Models," Econometrica, 77(6), 1865-1899.

JudD, K. L. (1998): Numerical Methods in Economics. The MIT press.

Krueger, A. B., And B. D. Meyer (2002): "Labor supply effects of social insurance," in Handbook of public economics, vol. 4, pp. 2327-2392. Elsevier.

Krueger, A. B., And A. Mueller (2010): "Job Search and Unemployment Insurance: New Evidence from Time Use Data," Journal of Public Economics, 94(3-4), 298-307.

Lancaster, T. (2004): An Introduction to Modern Bayesian Econometrics. Blackwell Publishing.

Layard, R., M. Barton, and A. Zabalza (1980): “Married Women's Participation and Hours," Economica, 47(185), 51-72.

LiU, J. (2009): "Risk Sharing Or Bargaining? The Impact of Spousal Labor Supply on Unemployment Duration," Social Science Research Network. 
LundBerg, S. (1985): "The Added Worker Effect," Journal of Labor Economics, 3(1), pp. 11-37.

Maloney, T. (1987): "Employment Constraints and the Labor Supply of Married Women: A Reexamination of the Added Worker Effect," Journal of Human Resources, 22(1), 51-61.

Maloney, T. (1991): "Unobserved Variables and the Elusive Added Worker Effect," Economica, 58(230), pp. 173-187.

Mankart, J., And R. Oikonomou (2011): "Household Search and the Aggregate Labor Market," London School of Economics.

Mattingly, M. J., And K. E. Smith (2010): "Changes in Wives' Employment When Husbands Stop Working: A Recession-Prosperity Comparison," Family Relations, 59(4), 343-357.

Meyer, B. D. (1990): "Unemployment Insurance and Unemployment Spells," Econometrica, 58(4), 757-782.

Moffitt, R. (1985): "Unemployment Insurance and the Distribution of Unemployment Spells," Journal of Econometrics, 28(1), 85-101.

Rothstein, J. (2012): "Unemployment Insurance and Job Search in the Great Recession," in Brookings Papers on Economic Activity: Fall 2011, ed. by J. W. David H. Romer. Brookings Institution Press.

Skrainka, B., And K. Judd (2011): "High Performance Quadrature Rules: How Numerical Integration Affects a Popular Model of Product Differentiation," Social Science Research Network. 
Smolyak, S. (1963): "Quadrature and Interpolation Formulas for Tensor Products of Certain Classes of Functions," Soviet Mathematics, Doklady, 4, 123.

Spletzer, J. R. (1997): "Reexamining the Added Worker Effect," Economic Inquiry, 35(2), 417-427.

Stephens, JR., M. (2002): "Worker Displacement and the Added Worker Effect," Journal of Labor Economics, 20(3), 504-537.

TAno, D. K. (1993): "The Added Worker Effect: A Causality Test," Economics Letters, 43(1), 111-117.

VAn Den Berg, G. J. (2001): "Duration Models: Specification, Identification and Multiple Durations," in Handbook of Econometrics, vol. 5, pp. 3381-3460. Elsevier. 


\section{A Appendix}

\section{A.1 Data Appendix}

In this appendix section, I describe some additional details related to my dataset and data preparation. The Stata code I used to construct these data is available at http://libra.virginia.edu/ in the file mystata_files.zip associated with my dissertation. This code downloads the SIPP data from the Census website and constructs the dataset I use for my analysis. See the readme.txt file for more detailed instructions.

\section{A.1.1 Sample Selection Criteria}

To construct my sample, I first start out with the universe of 130,858 married and divorced individuals in the 2004 and 2008 SIPP, and then I drop individuals due to various sample-selection criteria. Table 15 describes the criteria I use as well as how many individuals I drop due to each criteria. After imposing all these criteria, I am left with 19,244 individuals (9,622 Households). Note that married individuals who did not have a matching spouse could have a non-match if their spouse is present in the data but were dropped due to one of the criteria given earlier.

\section{A.1.2 Variable Definitions}

A detailed description of my employment-related variables and liquid asset variable is given as follows:

\section{Employment Indicators}

For the employment indicators, I make use of two types of employment variables in the SIPP: start and end dates of a job and weekly indicators of labor force status (employed, on layoff, etc.). A spouse is considered to be employed after the accept or reject decision in my model if they have a job at the end of the month, based on the job start and end dates, and the spouse is not on layoff. For example, I consider 
Table 15: Sample Selection Criteria

\section{Reason}

Always Divorced/Become Divorced Business Owners In School, Retired, or Disabled

Move to a New State

Error in Job ID

Imputation of UI or Labor Force Data

Person ID Changes Over Time

Break in Interview Spell

No Matching Spouse

In Sample Less Than 4 Months

Large Change in Wages

Unknown Job Start Date
Number Individuals Dropped

33,606

14,510

27,987

2,540

166

6,999

114

12,459

21,623

1,041

150

41

Table describes my sample selection criteria as well as the number of individuals dropped at each step. A description of some of the criteria is given as follows:

Error in Job ID: This error occurs when an individual has two jobs which have the same job id.

Imputation of UI or Labor Force Data: I drop imputed data because imputed values for these variables did not seem congruous with other variables. For example, many individual who have imputed UI data of a positive value are working and have continuous spells of employment. Person ID Changes Over Time: In a very small number of households, the time-invariant person ID appears to change over time.

Large Change in Wages: Drop households in which a spouse change jobs and the change in their wage is greater than $\$ 40$ or $150 \%$.

a spouse to be employed in March 2011 if the start date of their job is before March $31^{\text {st }}, 2011$, the end date is after March $31^{\text {st }}, 2011$, and the spouse is not on layoff in the last week of March 2011.

\section{Job Loss Indicators}

A spouse is considered to have lost a job at the end of the current month if, between the current month and the next month, the spouse has a break in their employment spell (indicated by the job start and end dates and the weekly employment indicators), 
and this break was not due to the spouse quiting to take another job (which is indicated by a variable when gives the reason a spouse's job ended). For example, a spouse is considered to have lost a job at the end of March 2011 if, between March $31^{\text {st }} 2011$ and April 30 ${ }^{\text {th }}, 2011$, the spouse is without employment (as indicated by the weekly labor force indicators or the job start and end dates) or employed but on layoff (as indicated by the weekly labor force indicators), and the spouse did not quit due to taking another job. If such a spouse has a different job in April 2011 but I do not classify them as loosing the job they had in March 2011, then the spouse is considered to have made an on-the-job transition.

\section{Durations of Employment and Non-Employment}

The number of months a spouse has had a job is constructed easily because the SIPP asks for the start dates all jobs individuals have during the course of the survey. The duration of non-employment is more complicated because the SIPP only ask the year a spouse last worked, not the month and year. With this information, I can construct bounds on the number of months a spouse has been without work. If a spouse is first interviewed in the middle of a year and they last had a job during that same year, then the difference between the upper bound and lower bound will be less than twelve months. To simplify my estimation routine, I take the average of the upper and lower bound as use that as a spouse's actual duration on non-employment. In the future, I plan to use a more sophisticated method in which I integrate over the distribution of potential duration of non-employment.

\section{Wages}

As discussed in the main body of text, wages are a spouse's hourly wage in 2010 dollars. Because a spouse's salary can increase over time within the same job and my 
model does not account for wages increases without a job transition, I keep wages constant by replacing them with the average wage the spouse has during their time with that employer.

Assets

As discussed in the main body of text, liquid assets are defined as a household's total wealth minus their home, vehicle, and business equity.

\section{A.2 Estimation Appendix}

In this appendix section, I discuss my estimation algorithm in more detail. The Fortran code I used to estimate my model and perform my policy experiments is available at http://libra.virginia.edu/ in the file myfortran_files.zip associated with my dissertation. See the readme.txt file for more detailed instructions.

\section{A.2.1 Value Function Approximation}

I construction an approximation of my value function for a new parameter using the formula given in equation (6) which involves kernel functions. For my kernel function, I use the Gaussian kernel using Silverman's rule of thumb for the bandwidth. To mitigate the curse of dimensionality, I combine some parameters into a linear index in order to reduce the number of arguments in the kernel function. For example, since the job offer parameters enter into the employment probability via a linear index, combing these variables into a similar index should allow me to make use of this restriction imposed by my model and gain more accurate approximations of the value function. Because some of these parameters are multiplied by spouse-specific variables, I take the average of these variables when constructing the linear index to be used in the value function.

In addition to using equation (6) for the value function, I also use equation (7) to update the value function. Imai, Jain, and Ching (2009) propose applying the Bellman 
operator only once per MCMC iteration using the previous proposal parameters as the parameters in the value function iteration. I make several modifications to their method which should make my algorithm more efficient. First, whenever I iterate the value function, I iterate the value function more than once. This should increase efficiency because many of the objects used to iterate the value function, such as the job offer probability, need to be calculated only once for a given parameter. Second, because iterating the value function more than once for each MCMC iteration would greatly slow down my algorithm, I only iterate the value function during some MCMC iterations. While this procedure may given me a smaller history of value function, each one of these value functions should have less error because I iterated the value function multiple times for that parameter. To obtain the parameters for my value function iterations, I draw a new parameter vector using a draw from a multivariate normal distribution in which the mean for this normal distribution is the mean of the recently accepted parameters.

Another modification I make is related to the starting values of the value function. Imai, Jain, and Ching (2009) set the initial value function to zero. However, because I have savings in my model, setting the value function to zero would cause household not to value the future and consume all their assets. Because this odd behavior could slow down the convergence of my algorithm, I instead start my algorithm with a set of parameter vectors centered around my initial guess of the parameter vector, and I then iterated the value function to convergence for each of these parameters. ${ }^{53}$. This helps ensure that I have a reasonable approximation of the value function even at the start of my algorithm.

\footnotetext{
${ }^{53}$ I use a low convergence criteria and maximum number of iterations to speed up this process
} 


\section{A.2.2 Interpolation Function}

My interpolation function is a multidimensional spline of my own creation. As discussed in section 6.3, I create a multidimensional spline which does not suffer from the curse of dimensionality. I do this by selecting one central state point and then constructing other points that deviate from this central point in only one or two dimensions. To explain how this is done, I first convert all my state variables to the $[-1,1]^{n}$ hypercube. ${ }^{54}$ Given this transformation, points in my state space take the form

$$
\begin{array}{rr}
(0, \ldots, 0, i, 0, \ldots, 0) & i \in\{-1,-, 5, .5,1\} \\
(0, \ldots, 0, i, 0, \ldots, 0, j, 0, \ldots, 0) & (i, j) \in\{(-1,-1),(-1,1),(1,-1),(1,1)\} .
\end{array}
$$

With these state points, I then construct my interpolation function by evaluating the value function at these points and then constructing a piecewise linear spline that "connects the dots." To speed up my interpolation function and value function iteration, I do not use the full set of interactions between two variables, only the interactions that have the most economic significance for my research questions of interest. ${ }^{55}$ I make the time-invariant mean of the wage distribution an argument in my interpolation function in order to reduce the number of arguments. I also make the amount of UI benefits a spouse could receive if they lost his or her job and the number of months a spouse has left of UI benefits arguments in my interpolation function instead of having the UI maximum benefit and maximum duration as arguments. In my own experimentation, I found that I could approximate the value function with my linear spline more easily with the former set of variables than the latter set.

\footnotetext{
${ }^{54}$ I put upper and lower bounds on some of my continuous variables to facilitate this conversion.

${ }^{55}$ The spreadsheet which indicates which pairs of variables have interaction is given in the zip file which contains my Fortran code.
} 


\section{A.2.3 Blocks}

As discussed in section 6.1, I divide my parameters into sets called blocks to speed up convergence of my algorithm. I put the job offer parameters into one block. I split the wage parameters into one block which consists of just the constant in the wage equation, one block which consists of the other parameters which affect the timeinvariance part of the mean of the wage distribution, and another block consisting of the remaining wage distribution parameters. ${ }^{56}$ Putting the wage constant into its own block helped me gain better movement for this parameter, which is important since this parameter has a large impact on how well my model's predicted wages match the observed distribution of wages. ${ }^{57}$ Putting the parameters which affect the timeinvariant part of the wage distribution into their own block speeds up my algorithm because individual-specific wage means are one argument in the interpolation function for my value function, so the value function does not need to be re-approximated in order to draw these parameters. I put each of the utility function parameters into their own block because this seemed to be the only way to get these parameters to move properly over the parameter space. I also put the unobserved heterogeneity variances and covariances into their own block, which allows me to use the Wishart distribution to draw the covariance matrix for the observed heterogeneity, which is faster than using MCMC.

\section{A.3 Likelihood Function}

I simplify the expression for my likelihood function with data augmentation, which allows me to avoid directly integrating over the distribution of my observed variables.

\footnotetext{
${ }^{56}$ These are the parameter for part-time jobs, the parameter for the unemployment rate, the probability a job is for part-time work, and the standard deviation of the wage distribution.

${ }^{57}$ By movement, I mean how often I am able to accept a new draw for this parameter in which the distance between the new parameter and accepted parameters is not too small.
} 
Let

$$
\ln \left(\mathscr{L}_{s, i, t}\left(Y_{s, i, t}^{*} \mid \theta, E V(S, \theta)\right)\right)
$$

denote the $\log$ likelihood contribution for household $i$ living in state $s$ at time $t$, in which $Y_{s, i, t}^{*}$ is a vector of dependent variables for this household at time $t$. This subcomponent of the likelihood function can be expressed as

$$
\begin{aligned}
& \ln \left(\mathscr{L}_{s, i, t}\left(Y_{s, i, t}^{*} \mid \theta, E V(S, \theta)\right)\right)= \\
& \left.1\left\{H_{s, i, m, t}^{\prime}>0\right\} \ln \left(\lambda_{m}(\cdot)\right)+1\left\{H_{s, i, m, t}^{\prime}=0\right\} \ln \left(1-\lambda_{m}(\cdot)\right)\right\} \\
& \left.+1\left\{H_{s, i, f, t}^{\prime}>0\right\} \ln \left(\lambda_{f}(\cdot)\right)+1\left\{H_{s, i, f, t}^{\prime}=0\right\} \ln \left(1-\lambda_{f}(\cdot)\right)\right\} \\
& \left.+1\left\{H_{s, i, m, t}^{\prime}>0\right\} \ln \left(g_{w, m}\left(W_{s, i, m, t}^{\prime} \cdot \cdot\right) g_{\mu}\left(\mu_{s, i, m, t}^{\prime}\right)\right)\right\} \\
& \left.+1\left\{H_{s, i, f, t}^{\prime}>0\right\} \ln \left(g_{w, f}\left(W_{s, i, f, t}^{\prime} \cdot \cdot\right) g_{\mu}\left(\mu_{s, i, f, t}^{\prime}\right)\right)\right\} \\
& \left.+1\left\{H_{s, i, m, t}^{\prime}=P T\right\} \ln \left(\pi_{m}^{P T}\right)+1\left\{H_{s, i, m, t}^{\prime}=F T\right\} \ln \left(1-\pi_{m}^{P T}\right)\right\} \\
& \left.+1\left\{H_{s, i, f, t}^{\prime}=P T\right\} \ln \left(\pi_{f}^{P T}\right)+1\left\{H_{s, i, f, t}^{\prime}=F T\right\} \ln \left(1-\pi_{f}^{P T}\right)\right\} \\
& \left.+1\left\{D_{s, i, m, t}=1\right\} \ln \left(f_{w}\left(W_{s, i, m, t}^{\text {data }} \mid \cdot\right)\right)\right\} \\
& \left.+1\left\{D_{s, i, f, t}=1\right\} \ln \left(f_{w}\left(W_{s, i, f, t}^{\text {data }} \mid \cdot\right)\right)\right\} \\
& \left.+\left(1-1\left\{H_{s, i, m, t}^{\prime}=0, H_{s, i, f, t}^{\prime}=0\right\}\right) \operatorname{Pr}\left(D_{s, i, t} \mid \cdot\right)\right\} \quad \text { Choice probability } \\
& +\ln (\chi(\cdot))\} \quad \text { Birth probability } \\
& +1\left\{\widetilde{H}_{s, i, m, t}>0, H_{s, i, m, t+1}=0\right\} \ln \left(\eta_{m}(\cdot)\right) \\
& \left.+1\left\{\widetilde{H}_{s, i, m, t}>0, H_{s, i, m, t+1}>0\right\} \ln \left(1-\eta_{m}(\cdot)\right)\right\} \\
& \left.+1\left\{\widetilde{H}_{s, i, f, t}>0, H_{s, i, f, t+1}=0\right\} \ln \left(\eta_{f}(\cdot)\right)\right\} \\
& \left.+1\left\{\widetilde{H}_{s, i, f, t}>0, H_{s, i, f, t+1}>0\right\} \ln \left(1-\eta_{f}(\cdot)\right)\right)
\end{aligned}
$$




$$
\left.\begin{array}{r}
+1\left\{\widetilde{H}_{s, i, m, t}>0, H_{s, i, m, t+1}=0, B_{s, i, m, t}>0\right\} \ln \left(\psi_{m}(\cdot)\right) \\
+1\left\{\widetilde{H}_{s, i, m, t}>0, H_{s, i, m, t+1}=0, B_{s, i, m, t}=0\right\} \ln \left(1-\psi_{m}(\cdot)\right) \\
+1\left\{\widetilde{H}_{s, i, f, t}>0, H_{s, i, f, t+1}=0, B_{s, i, f, t}>0\right\} \ln \left(\psi_{f}(\cdot)\right) \\
+1\left\{\widetilde{H}_{s, i, f, t}>0, H_{s, i, f, t+1}=0, B_{s, i, f, t}=0\right\} \ln \left(1-\psi_{f}(\cdot)\right),
\end{array}\right\}
$$

in which $H_{s, i, p, t}^{\prime}$ is a spouse's offered hours worked and $\widetilde{H}_{s, i, p, t}$ is a spouse's hours of work after the accept decision but before the job loss event. Measurement error in assets is not included in $\ln \left(\mathscr{L}_{s, i, t}\left(Y_{s, i, t}^{*} \mid \theta, E V(S, \theta)\right)\right)$ because liquid assets are not measured every month in the SIPP panel. The overall likelihood contribution for household $i$ in state $s$ can be expressed as

$$
\begin{array}{r}
\ln \left(\mathscr{L}_{s, i}\left(Y_{s, i}^{*} \mid \theta, E V(S, \theta)\right)\right)=\sum_{t=1}^{T_{s, i}} \ln \left(\mathscr{L}_{s, i, t}\left(Y_{s, i, t}^{*} \mid \theta, E V(S, \theta)\right)\right)+ \\
\ln \left(f_{A}\left(A_{s, i}^{\text {data }} \mid \cdot\right)\right)+\ln \left(g_{\nu}\left(\nu_{s, i}\right)\right)+\ln \left(f_{0}(\cdot)\right)
\end{array}
$$

in which $f_{A}\left(A_{s, i}^{\text {data }} \mid \cdot\right)$ is the product of the asset error densities for each time assets are measured, $g_{\nu}\left(\nu_{s, i}\right)$ is the joint density of unobserved heterogeneity, and $f_{0}(\cdot)$ is the density for the initial conditions, which I set to 1 in order to simplify my estimation program. The likelihood for the whole sample is just the sum of the individual household likelihoods presented in the above equation. I do not make use of survey weights when evaluating the likelihood function. 


\title{
A.4 Supplemental Tables and Figures
}

\author{
Table 16: Description of Notation
}

Subscript
$i$
$k$
$n$
$p$
$r$

$s$
$t$

\section{Symbol}

$A_{t}$

$B_{p, t}$

$C_{t}$

$C_{\min }$

$D_{p, t}$

$\widehat{E V}^{k}(\cdot)$

$f_{C}(\cdot), f_{L}(\cdot)$

$g_{w, p}(\cdot)$

$g_{\mu}(\cdot)$

$g_{\nu}(\cdot)$

$H_{p, t}$

$J_{t}$

$K_{h}$

$L_{p, t}$

$R_{s, t}$

$S_{t}$

$V(\cdot)$

$W_{p, t}$

$X_{p, t}$

$Y_{i}$

$$
\begin{aligned}
& H_{p, t}^{\prime}, W_{p, t}^{\prime}, \mu_{p, t}^{\prime} \\
& \widetilde{W}_{p, t}\left(D_{p, t}\right), \widetilde{H}_{p, t}\left(D_{p, t}\right), \\
& \quad \widetilde{\mu}_{p, t}\left(D_{p, t}\right)
\end{aligned}
$$

$$
\begin{aligned}
& \alpha \\
& \beta \\
& \epsilon_{t}(\cdot) \\
& \\
& \eta_{p}(\cdot) \\
& \theta \\
& \lambda_{p}(\cdot) \\
& \mu_{p, t} \\
& \nu_{r, p}
\end{aligned}
$$

\section{Meaning}

Households

Iterations in my algorithm

Previous iterations in my algorithm

Spouses ( $p$ for person)

Unobserved heterogeneity

$w$ for the wage distribution

U.S. states (including D.C.)

Time

\section{Meaning}

Level of assets

UI benefits

Consumption

Minimum consumption level

Indicator of accepting a job offer

Approximation of expected value function

Consumption and leisure functions

Wage density for spouse $p$

Density for non-pecuniary benefits

Density for unobserved heterogeneity

Hours worked (none, part-time, full-time)

Vector of employment-related variables

Multivariate kernel with bandwidth $h$

Length of time with or without a job

Unemployment rate

Vector of state variables

Value function

Hourly wage

Demographic variables

Set of outcomes for household $i$

Offered wage, hours worked, and non-pecuniary benefit

Accepted wage, hours worked, and non-pecuniary benefit

Linear coefficients for functions in model

Discount factor

Time-choice-specific shocks for accepting a job offer

Probability a spouse loses a job

Vector of parameters

Probability of receiving a job offer

Non-pecuniary benefit that a job provides Unobserved heterogeneity

\author{
Possible Values \\ $1, \ldots, I$ \\ $1, \ldots, K$ \\ $N(k), \ldots, k-1$ \\ $m, f$ \\ $w$ \\ $1, \ldots, 51$ \\ $1, \ldots, T$
}

Possible Values
$[\varpi, \infty)$
$\Re^{+}$
$\Re^{+}$
$\Re^{+}$
0,1
$\Re$
$\Re$
$\Re^{+}$
$\Re^{+}$
$\Re^{+}$
$0, P T, F T$
$J_{t}$ is a vector
$\Re^{+}$
$\mathbb{N}^{+}$
$\Re^{+}$
$S_{t}$ is a vector
$\Re$
$\Re^{+}$
$X_{p, t}$ is a vector
$Y_{i}$ is a vector

$\alpha$ is a matrix

$[0,1)$

$\Re$

$[0,1]$

$\theta$ is a vector

$[0,1]$

$\Re$

$\Re$ 
$\pi_{p}^{P T}$

$\varpi$

$\rho(\cdot)$

$\sigma_{c}$

$\sigma_{w}$

$\chi(\cdot)$

$\psi_{p}(\cdot)$

$\mathscr{L}_{i}(\cdot)$

$\mathscr{M}(\cdot)$
Probability a job offer is for part-time work

$[0,1]$

Asset lower bound

$\Re^{+}$

Proposal density in Metropolis-Hastings algorithm $(0,1)$

Coefficient of relative risk aversion

$\Re^{+}$

Variance for log-normal wage distribution

$\Re^{+}$

Probability a child is born

$[0,1]$

Probability a job-loser is eligible for UI

$[0,1]$

Likelihood function

$\Re^{+}$

Metropolis-Hastings probability 
Figure 5: Flow Chart for Sequence of Events in the Model

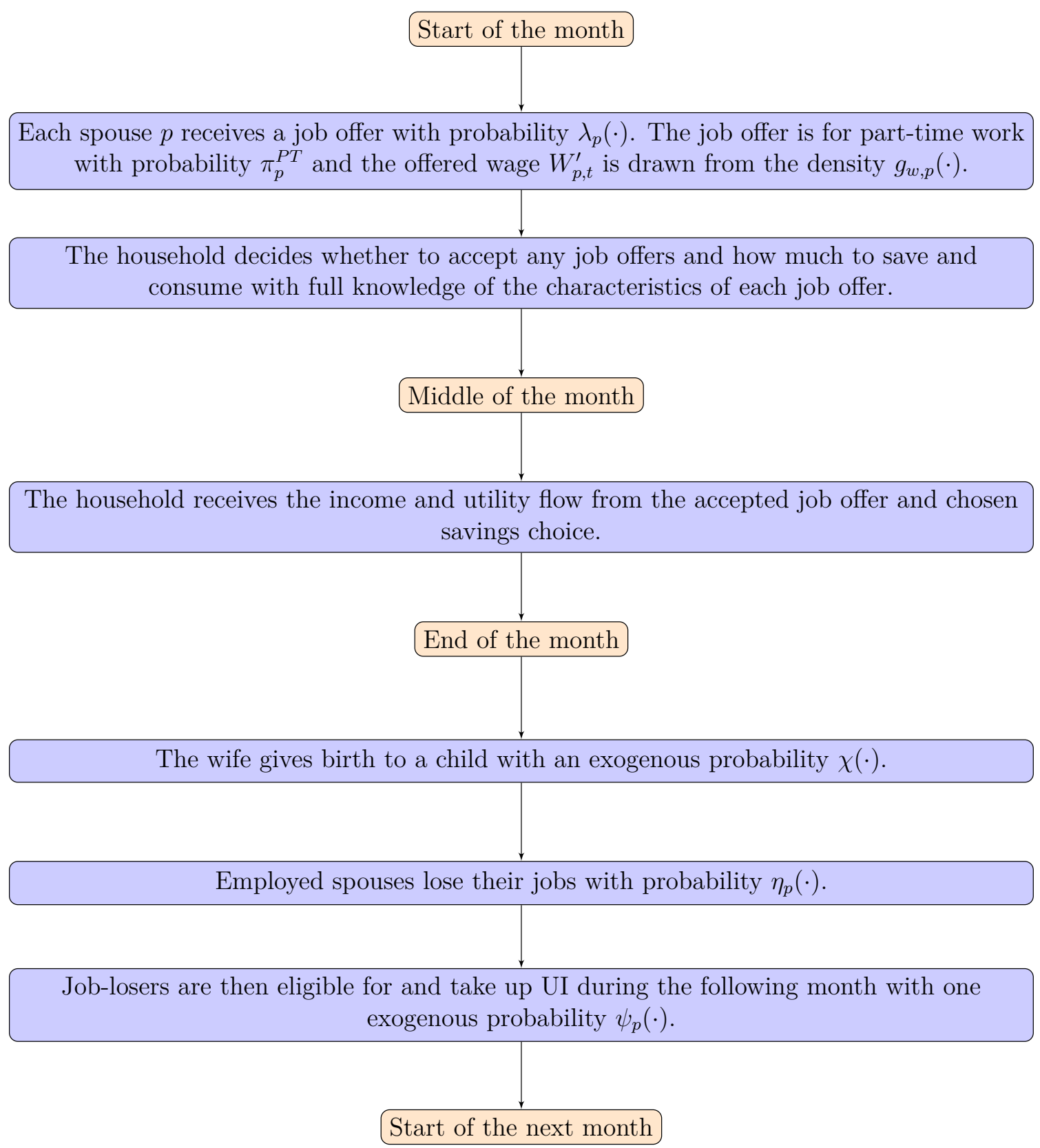

